University of South Florida

DIGITAL COMMONS

Digital Commons @ University of

@ UNIVERSITY OF SOUTH FLORIDA

South Florida

\title{
The Underdog Effect: Definition, Limitations, and Motivations. Why Do We Support Those at a Competitive Disadvantage?
}

Nadav Goldschmied

University of South Florida

Follow this and additional works at: https://digitalcommons.usf.edu/etd

Part of the American Studies Commons

\section{Scholar Commons Citation}

Goldschmied, Nadav, "The Underdog Effect: Definition, Limitations, and Motivations. Why Do We Support Those at a Competitive Disadvantage?" (2005). USF Tampa Graduate Theses and Dissertations.

https://digitalcommons.usf.edu/etd/2899

This Thesis is brought to you for free and open access by the USF Graduate Theses and Dissertations at Digital Commons @ University of South Florida. It has been accepted for inclusion in USF Tampa Graduate Theses and Dissertations by an authorized administrator of Digital Commons @ University of South Florida. For more information, please contact digitalcommons@usf.edu. 
The Underdog Effect: Definition, Limitations, and Motivations.

Why Do We Support Those at a Competitive Disadvantage?

by

Nadav Goldschmied

A thesis submitted in partial fulfillment

of the requirements for the degree of

Master of Arts

Department of Psychology

College of Arts and Sciences

University of South Florida

Major Professor: Joseph Vandello, Ph.D.

Judith Bryant, Ph.D.

Kristen Salomon, Ph.D.

Date of Approval:

July 19, 2005

Keywords: justice, competition, schadenfreude

(C) Copyright 2005, Nadav Goldschmied 


\section{Table of Contents}

List of Tables $\quad$ V

List of Figures $\quad$ vi

Abstract vii

Introduction $\quad 1$

Identification, Esteem, and Emotional Affiliation of Third Party Observers 1

The Appeal of the Underdog 5

$\begin{array}{lr}\text { Schadenfreude as a Possible Explanation } & 8\end{array}$

$\begin{array}{ll}\text { Justice-Based Motivations } & 13\end{array}$

$\begin{array}{ll}\text { Utilitarian-Based Motivations } & 15\end{array}$

$\begin{array}{ll}\text { Overview of the Present Studies and Hypotheses } & 17\end{array}$

Study 1: Exploring the Underdog Construct 20

$\begin{array}{ll}\text { Method } & 20\end{array}$

$\begin{array}{ll}\text { Participants } & 20\end{array}$

$\begin{array}{ll}\text { Procedure } & 21\end{array}$

Results - Study 1a 23

Who is the underdog? $\quad 24$

Which team would you like to win? 24

Which team would you root for? 26

Social Dominance Orientation 26 
Results - Study 1b: Sports, Politics, and Business Vignettes

$\begin{array}{ll}\text { Sports Vignettes } & 27\end{array}$

Which team is going to win? $\quad 27$

Who is the underdog? $\quad 27$

Which team would you like to win? 27

Which team would you root for? $\quad 28$

Social Dominance Orientation 28

$\begin{array}{ll}\text { Political Vignette } & 30\end{array}$

Which candidate is going to win the elections? 30

Who is the underdog? $\quad 30$

Who would you like to win? 31

For whom would you vote? 31

Social Dominance Orientation 31

Business Vignette 31

Which restaurant is going to do better? 31

Who is the underdog? 31

Who would you like to succeed? 31

Where would you dine? $\quad 32$

Social Dominance Orientation $\quad 32$

$\begin{array}{ll}\text { Discussion } & 32\end{array}$

Studies 2-4: Underdog or Schadenfreude? 34

Study 2: Framing Competitions as Desire to See Win or Lose 35

$\begin{array}{ll}\text { Method } & 35\end{array}$ 
Procedure

Results

Discussion

Study 3: The Role of the Spoiler

Method

Participants

Procedure

Results

Which team is going to win?

Who is the underdog?

Which team would you like to win?

Which team would you root for?

Social Dominance Orientation

Discussion

Study 4: Attentional Focus While Observing a Competition

Method

Participants

Procedure

Results

Pre-Video underdog support

Which team would you like to win?

Which team would you root for? 
Memory (post-video watching): Recall 46

Memory (post-video watching): Recognition 46

Exploratory analyses about attributions for performance $\quad 47$

$\begin{array}{ll}\text { Discussion } & 49\end{array}$

General Discussion $\quad 51$

$\begin{array}{ll}\text { Limitations } & 55\end{array}$

$\begin{array}{ll}\text { Future Directions } & 57\end{array}$

$\begin{array}{ll}\text { References } & 59\end{array}$

$\begin{array}{ll}\text { Appendices } & 65\end{array}$

Appendix A. Study 1 Materials: Exploring the Underdog Construct 66

Appendix B. Study 2 Materials: Framing Competitions as Desire to See

Win or Lose $\quad 82$

Appendix C. Study 3 Materials: The Role of the Spoiler 88

Appendix D. Study 4 Materials: Attentional Focus While Observing a

$\begin{array}{ll}\text { Competition } & 95\end{array}$ 


\section{List of Tables}

Table 1 Desire for each team to win the game as a function of expectations for success and resources, Study $1 a$

Table 2 Desire for each team to win the game as a function of past history of success and resources, Study $1 b$ 


\section{List of Figures}

Figure 1 Support extended to underdogs/ top dogs under spoiler and nonspoiler scenarios, Study 3.

Figure 2 Percentage of recognition of underdog/top dog players when resources are present or not, Study 4. 
The Underdog Effect: Definition, Limitations, and Motivations.

Why Do We Support Those at a Competitive Disadvantage?

\begin{abstract}
From politics to sports to business, people are quick to categorize those at a competitive disadvantage as 'underdogs'. Moreover, there is ample anecdotal support that most people do not hesitate to align themselves with underdogs, a phenomenon called "the underdog effect". A series of studies were conducted to examine the scope and limitations of the underdog effect. The first study explored the extent of the underdog effect and determined that resources play a crucial role in forming alliances with those whom we perceive to have the lower chance to succeed. A second series of experiments assessed whether participants, who demonstrated the underdog effect, did truly support those at a competitive disadvantage or merely rooted against the favorite. The first experiment in this series framed questions in terms of either losing or winning, thus forcing the responders to pick the more salient of their perceptions of a novel competition scenario. Support for the underdog was found to be more extreme than rooting against the top-dog. The next experiment in this series explored the human perception under “spoiler” condition, when the underdog does not have much to gain from winning the competition, but the stakes are high for the top dog due to possible adverse repercussions above and beyond of the present competition. Spoilers were not supported more than non-spoilers. Finally, the last series of studies used memory as an
\end{abstract}


indirect measure of focus of attention. Some evidence for rooting against top dogs was found. 


\section{Introduction}

People are drawn to competitions pitting rivals with disparate power. David vs. Goliath. The USA hockey amateur team vs. the mighty Russians in the 'miracle on ice'. Truman vs. Dewey in the 1948 race for the presidency. Competition plays a major role in social interaction in most cultures (but see Bonta, 1997, for exceptions). Given the importance of competition across many situations, it would be highly valuable to explore not only the nature of the competition itself but also the way people shape their opinions and alliances about competitive situations in which they don't take an active part. This research project examines three core aspects of imbalanced competitive situations: What are the elements that make an entity qualify as an underdog? What do observers feel when they approach a competition of disparate power: in essence, do they feel sympathy towards the 'little guy' or do they wish for the mighty to fall? And, finally, what drives unattached observers to support the Davids of the world? Is it the sense of justice, which is aroused by the uneven situation, or is it a utilitarianism motive, which proclaims that third-party onlookers buy an 'insurance policy’ by supporting the underdog? After all, by definition, the underdog is expected to lose and one can only gain if the underdog surprisingly overcomes the top dog.

\section{Identification, Esteem, and Emotional Affiliation of Third Party Observers}

A good deal of research has focused on partisan observers and the way they perceive competition. In an early classic, Hastorf and Cantril (1954) studied observers 
who were known to be supporters of a football team and showed that their perception was largely influenced by selective interpretation, the tendency to shape perceptions to fit one’s own perspective. Their study, “They Saw a Game,” showed that students from Dartmouth and Princeton, whose teams competed on the football field, couldn't agree on the number of fouls committed in the game, who was responsible, or which team "started the rough play” (e.g., 86\% of Princeton students, but only 36\% of Dartmouth students said "Dartmouth”).

More recently, Thompson (1995) created a work environment setting in which participants role-played employer-employee job contract negotiation. She divided the participants into three levels of involvement: actual negotiators, partisan observers who were assigned to empathize with one of the sides, and non-partisan observers. The latter group made judgments that were different from the other two with respect to the level of friendliness and honesty attributed to each side, but, more importantly, this group was able to make more accurate judgments of the situation overall. Thompson, therefore, demonstrated how easy it was to shape one's perception based on his or her assigned alliance with one of the sides.

Other research has shown how identification with a group can be altered by the group’s success (End, Dietz-Uhler, Harrick, \& Jacquemotte, 2002; Sloan, 1989; Wann, Tucker, \& Schrader, 1996). Cialdini and colleagues (1976), for example, followed college students' post-outcome behaviors after football games. They found that, following a home victory, students were more likely to wear clothes bearing the name of their university and were more likely to use inclusive language (i.e., "we," "us”) than after a loss. The authors termed the fans' behavior "basking in reflected glory” (or 
"BIRGing") and claimed that this behavior derives from self-presentation motives. This tendency, in turn, can be best understood in light of the social identity theory (Tajfel \& Turner, 1986), which proposes that individuals are motivated to gain positive self-esteem through their group memberships. Tajfel (1978) described this as "that part of an individual's self-concept which derives from his knowledge of his membership of a social group together with the value and emotional significance attached to that membership”. According to Sloan (1989), what one’s team achieves, one personally achieves.

Moreover, the complementary phenomenon of "CORFing”, or "cutting off reflective failure," was also found as a strategy for fans of losing teams (Cialdini et al., 1976; Wann \& Branscombe, 1990). Those fans tended to attempt to disassociate from the losing team in social settings so that others would not judge them in an unfavorable light.

Affiliating with a team or group can also influence self-evaluations. For example, Hirt, Zillmann, Erickson and Kennedy (1992) demonstrated that fans who watched their team win estimated their own performance on a set of unrelated tasks as higher compared to a control group. In the same experiment a third group of fans who watched a loss of their beloved team showed the least level of self-esteem. For those fans, their team performance had similar effects as if they were failing personally. Schweitzer, Zillmann, Weaver, and Luttrell (1992) have even found that fans distressed over their team's loss estimated a feared war with Iraq as significantly more likely and more devastating than did fans whose team won. 
All the research described above dealt with partisan observers, or individuals who in some capacity had a past history of vested interest or were assigned to identify with one side. Preexisting affiliations carry with them emotional attachment and commitment to the entity in its struggle to succeed. It is, therefore, important to note the difference between observers who are motivated interpreters of an event (i.e., "fans," "patrons”) and those who have no pre-existing affiliations.

Most people are 'fans' or supporters of a cause, team, or candidate only when it pertains to a limited realm of issues of immediate concern to them (Kinder, 1998). However, it does not preclude them from having an immediate opinion or affective reaction when they encounter a novel situation. Zajonc (1980) defined the primacy of affect as the precedence in time that affective reactions take over cognitive ones and their immediate, involving, inescapable, and compelling nature. Other researchers (Epstein, 1984; Lazarus, 1982) challenged this model, suggesting instead a primitive form of nonconscious cognition operating before the affective stage emerges. Regardless of which of these two major theories holds true, it appears that people do not require much information or strong pre-existing notions to form an opinion or emotions when it comes to dealing with novel situations.

Based on social identity theory and BIRGing and CORFing behaviors, it would be reasonable to expect that non-partisan observers of an imbalanced competitive event would also support the side with the best chance of success. Dominant parties with a proven past track record might be expected to offer attractive targets with which to identify, if self-esteem is closely tied with identification with groups. Hogg and Abrams (1988) were able to establish that a process of selective differentiation between in-groups 
and out-groups serves the purpose of obtaining a relatively positive self-evaluation that endows the individual with a sense of well-being, enhanced self-worth and esteem. However, contrary to this logic, there is plenty of anecdotal evidence that unattached observers in fact support those who are at a competitive disadvantage.

\section{The Appeal of the Underdog}

Classic examples of rivals with a disparity of power are numerous and extend from the early days of humankind, ranging from the paragon biblical story of David and Goliath, throughout mythology when Troy faced the almighty Greeks, to modern day geopolitical examples pitting the USA as the lone superpower against much less powerful rivals. Sometimes the lopsided struggle involves groups (for example, the USA hockey amateur team versus the mighty Russians in the "miracle on ice”), while at other times the rivalry is between individuals (for example, Truman versus Dewey’s famous come from behind to win the presidency in 1948).

When such disparities of power or expectations exist, one side is often labeled as an "underdog." The term underdog surfaced first in the $19^{\text {th }}$ century and since then came to signify “one at a disadvantage and expected to lose” (Hyper Dictionary Online, 2004). The phrase originated from dog fighting, a common practice in those days, in which the losing dog was declared as the 'under dog' because it would usually submit, rolling over on its back, allowing the stronger dog to tower over him. The weaker dog then was literally under the stronger one. One should note that being an underdog, based on this definition, exists for the most part in the time before an outcome is determined. 
The Merriam-Webster dictionary lists two definitions of an underdog: (1) a loser or predicted loser in a struggle or contest; and (2) a victim of injustice or persecution (Merriam Webster, 1994). While the first characterization is similar to the one described above, the second raises the issue of justice in determining who qualifies to be labeled as an underdog.

Despite the commonness of underdogs, almost no research has examined people's tendency to back (or not back) them. Contrary to the notion that non-affiliated observers tend to support the stronger side (following the assumption of social identity theory), there is some limited evidence that individuals are drawn to supporting underdogs rather than dominant entities. For instance, Frazier and Snyder (1991) demonstrated that students exposed to short scenarios describing a competition between a hypothetical, heavily favored team and a lesser counterpart in a seven-game playoff series (with no other information available) showed a marked favoritism (88.1\%) towards the underdog. After the participants made their judgment, they were told that the heavily favored team lost the first three consecutive games and thus was on the brink of elimination from the series. Faced with the new reversal of roles, about half of the participants (49 out of the 99 people who favored the original underdog) changed their allegiances and preferred that the original less capable team lose the next game, a possible testament to the transient nature of who qualifies as an underdog. Moreover, demonstrating once again how fickle the underdog attribution process is, when encountered with a third and last scenario in which the two teams were tied at three games, each going to the last deciding match in the series, 37 out of 44 participants changed their allegiances once again and expressed their hope for a win for the original underdog. 
Markus, McGuire, Allison, and Eylon (2004), in an unpublished work, were able to replicate Frazier and Snyder's (1991) findings and to show that participants extended support to underdogs both in the sport arena and in the business domain. Their definition of an underdog was based on past success and failure history. In both sports and business settings, a majority of the participants were able to easily categorize the side in a disadvantage as carrying the label of an underdog ( $80 \%$ and $82 \%$, respectively). Moreover, participants reported that they would be much more pleased if the underdog won, compared to the top dog.

Ceci and Kain (1982) used the presidential race of 1980 between Carter and Reagan to demonstrate the "underdog effect". They showed their participants fake polls indicating either of the candidates holding a dominant lead. Among the participants who were exposed to a Carter lead, $44 \%$ declared themselves in Reagan's camp, versus roughly 30\% in Carter's, while 25\% remained undecided. When other participants were notified that Reagan was holding a substantial lead in the polls, only 21\% declared themselves in his favor while approximately 53\% aligned themselves with Carter. Moreover, the authors divided the participants into those who had an initial inclination towards one of the candidates before the polls were introduced (i.e., 'fans') and those who had no inclination at all (the 'undecided'). Even among the first group, 22\% of those belonging to the Reagan camp and 30\% of the Carter camp shifted their support based on the polls showing dominance of their candidate. Among the early-undecided group the shift was even more staggering, as $66 \%$ changed their minds to oppose the dominant frontrunner. 
The sound support extended to the underdog is especially puzzling in light of the Webster's dictionary definition, which characterizes the underdog as a loser (Merriam Webster, 1994). In turn, Webster's definition for a loser is: (1) one that loses especially consistently; (2) one who is incompetent or unable to succeed; and (3) something doomed to fail or disappoint (Merriam Webster, 1994). The dictionary states that the idiom sprang from student slang in the mid 1950’s and came to signify a "hapless person". It has obvious negative connotations for the individual it labels. Why, then, do people overwhelmingly support an entity, which, in essence, is a loser?

But this anomaly goes even a step further. Sympathy for underdogs may extend beyond rooting for them as an observer to actively seeking to label oneself as such. It is not uncommon to find two competitors vying for the underdog label to shy away from any semblance of superiority prior to the competition itself. In both sports and politics, all parties seem reluctant to hold the label of frontrunner, and willing or even happy to embrace the label of underdog. Quotes like "Former Vermont Gov. Howard Dean and Sen. John Kerry of Massachusetts lead in the latest tracking polls in New Hampshire, but both are calling themselves underdogs as they retool their campaigns in a changed political landscape." (www.cnn.com, 1/21/04) are plenty. It seems that there is an intuitive understanding that people prefer and sympathize with underdogs.

In the present studies, people were exposed to competitions that pitted two sides with some type of inequity—either having differing expectations for performance, having disparities in resources, or both. This allowed for an examination of people's definition of underdogs, as well as an examination of the conditions under which people support disadvantaged entities. 


\section{Schadenfreude as a Possible Explanation}

There could be multiple motivations behind the sympathy and support that people extend to the underdog. One possibility is that people do not so much root for the underdog as much as they root against the more dominant entity. That is, what may appear to be sympathy may instead be motivated more by pleasure in seeing a powerful figure or team knocked off its pedestal, a phenomenon known as schadenfreude, or the joy people take in the fall from grace of others. Sport, as an example, is by definition a zero sum game: While one team is winning, its opponent is invariably losing. It is possible that standing behind the underdog is just the mirror image of aspiring for the strong side to lose. Maybe, because of social desirability among other possible reasons, nonpartisan observers publicly support the underdog while privately aspiring for the mighty to fall.

People are taught from infancy to think that good things that happen to others should please them, while bad things that happen to others ought to be upsetting and disturbing to the 'moral' person. Sometimes, as we mature, the feeling of joy in the misfortune of others creeps on us. Nietzsche (1887/ 1967) was the first to label the concept of schadenfreude as an emotional reaction in the repertoire of feelings experienced by human beings. He described it as the malicious pleasure that people take in the misfortune of others. Heider (1958) claimed that schadenfreude is counterproductive in the social setting because pleasure is a "discordant” reaction to another's downfall and hence it establishes an antagonistic relationship between the person who experiences it and its target. Schadenfreude is opportunistic by nature, indirect and passive. In other words, people who experience schadenfreude do not actively seek the 
demise of other people or plan for it, but feel a burst of joy when encountering news about a setback someone else suffered. Nietzsche added that seeing other people suffer and experiencing schadenfreude while not actively engaging in direct competition is socially less acceptable.

Smith and colleagues (1996) sought to verify the existence of schadenfreude in everyday experiences. They showed participants a short videotape of a prospective medical student describing himself. The student was made to appear either superior or average. An epilogue informed participants that the student was recently caught stealing and thus would not be admitted to medical school. Participants who watched the interview of the better-qualified student were more pleased upon learning that this person suffered the setback than participants who watched his average counterpart, thus supporting the schadenfreude phenomenon and introducing envy as a predisposed state to the joy people take in others' fall from grace.

In their research on the elections of 1980 described above, Ceci and Kain (1982) determined that polls did not create positive feelings towards the underdog but, instead, created a negative reaction towards the candidate depicted as having a dominant position. Thus, participants, who were shown one contender as leading in an early stage, swayed away from him (a ranking of 3.27 on a 7-point scale, as opposed to a 3.94 ranking in a control group, which had never been exposed to the polls). But when the same group was presented later on with another poll indicating a shift in the polls towards the previous underdog, making him a dominant frontrunner, the participants shifted their support once again back to the current underdog. This shift, however, was approximately to the same range of the control group (3.9), convincing the authors that "the seemingly large shifts 
between the ...inconsistent conditions were due to oppositional reactivity, not necessarily underdog feelings. Subject shifting....did not surpass the initial position ” and "dominance information did not evoke a positive move towards the underdog, merely a movement away from whoever was currently being touted as dominant” (p. 240).

Feather and Sherman (2002) tested the hypothesis that schadenfreude would be more closely related to resentment (defined as publicly expressed when the outcome is undeserved) and a wish to correct a perceived injustice than to envy (which is privately held and can occur without a sense of injustice or resentment). Their participants responded to scenarios in which a student with a record of either high or average achievement that followed high or low effort subsequently suffered failure under conditions where there was either high or low personal control. The authors found that resentment about the student's prior achievement could be distinguished from envy, based on the results of factor analysis. Schadenfreude about the student's subsequent failure was predicted by resentment and not by envy; thus, deservingness was a key variable in the models that were tested.

Leach and colleagues (Leach, Spears, Branscombe, \& Doosje, 2003) demonstrated schadenfreude in the sports domain as it manifests itself in inter-group relations. Dutch soccer fans were asked about their feelings in regards to failure of the German national team in the international arena. Based on pilot studies and history, the researchers were able to establish that the two nations were perceived by the Dutch as competitors and, hence, predicted and subsequently found that the latter would be likely to experience schadenfreude in the face of a German defeat by a third party. The authors argued that, although it is generally unacceptable to experience malicious feelings such as 
dislike, domain interest (i.e., the perceived importance of the issue at hand) and inferiority threat (in this case, based on history and relative size of the two nations) might make schadenfreude seem more acceptable.

But why would we expect nonpartisan observers who had no prior knowledge of two entities to develop schadenfreude after reading short vignettes describing competitions of disparate strength? A possible answer may lay in social comparison theory (Festinger, 1954; Tesser, 1991; Wills, 1991). In this case, the envy or resentment is literally defined by a comparison process. Following the finding that sympathy is more easily generated by misfortune happening to average, rather than superior, people, Brigham and colleagues (Brigham, Kelso, Jackson, \& Smith, 1997) proposed that schadenfreude arises when people feel that a misfortune befalling on others removes the negative, self-related effects of an invidious comparison. Moreover, because of its distinct features (i.e., opportunistic, indirect and passive), schadenfreude becomes a welcomed guest by a nonpartisan observer with little or no effect whatsoever on the developing nature of the competition.

Whatever basic process takes precedent - schadenfreude or rooting for the underdog - the manifested outcome by non-partisan observers is the same (i.e. rooting for the underdog and against the top dog falls in 'real life' into the same category of siding with one side against the other). On the other hand, the possible underlying motivations behind the support they extend could be diverse. Some of the possible motivations are reviewed below. 


\section{Justice-Based Motivations}

People are motivated to believe that the world is basically a just place (Lerner, 1975, 1977). Lerner (1977) was the first to identify justice as a primary motive rather than a derivate of other motives, such as self-interest or normative roles.

Conditions of scarcity of resources call for assessment of resource allocation based on the justice argument of deservingness (Skitka and Tetlock, 1992). In the current study, unattached observers are asked to make decisions whom to support based on past performance. Winning eventually will belong to only one party of the two direct competitors (hence the scarcity of resources). It may be reasonable to assume, therefore, that when faced with a situation of remarkably uneven history of success and failure, the unattached observer will be called to examine his or her inner concepts of justice and the 'distribution of fate' in the world. Deutsch (1985) labels such a scenario 'relative deprivation,' a violation of a perceived entitlement, which is a driving force behind the arousal of the sense of injustice. In other words, third party observers may implicitly introduce the term of fairness to their assessment of the situation. They may ask themselves if the distribution of rewards is fair or unfair in relation to both entities as well as to general principles of justice and legitimized norms that are part of the social fabric.

Skitka and Tetlock’s (1992) contingency model of resource distribution proposes that after an allocator of resources makes a determination that a situation of insufficiency exists, she or he turns to attributional analysis. The question then is: are the claimants personally responsible for their predicament or not? The next stage involves a situation in which the resources are still in short supply after the internal-control claimants were denied resources. Now the allocator has to appraise claimants' deservingness: Are some 
claimants' needier than others and would providing aid to some be more effective than to others? The authors also mention that the allocation will be affected by the ideology of the allocator and draw from findings by Carroll, Perkowitz, Lurigio and Weaver (1987), who identified two clusters of ideological variables: ‘cognitive conservatism' and 'liberal humanism' which shaped allocation behavior.

Deutsch $(1975,1985)$, in the context of distributive justice, suggests that in competitive situations in which productivity is highly valued, equity or the principle of outcome distribution among entities will be based on the proportion of input or contribution, while the principle of equality (distributing outcomes based on need) will gain the upper hand in cooperative situations. Thus, the nature of the situation may elicit different and competing justice principles.

One could easily argue that justice concerns do not serve at the basis of underdog effect. Past research (Frazier \& Snyder, 1991; Markus, McGuire, Allison, \& Eylon, 2004) has established the support for the underdog without stating any qualifications on the 'traits' of the competing sides (that is, in these experiments, participants responded to brief scenarios in which little was known about the actors other than their standings as underdogs or top dogs). It is possible that the past history of losing is attributed to lack of effort, general ineptitude and squandering of resources. If this is the case, the justice motive should not play a significant role in supporting the underdog based on the concept of "deservingness" (Feather, 1991). An alternative possibility is that detached observers assume otherwise (i.e., a match between lack of success and a state of relative deprivation) and base their favoritism towards the weaker side as part of an overall perception of the world as an unfair place. Does the support extended to the underdog 
offer people the opportunity to symbolically rectify the unjust world they perceive? It is possible that there is an element in the direct competition scenario, which sharpens this notion, and pushes the majority of people to align themselves with the underdog.

Even if this is the case, one could argue about the degree of difference one game or a rudimentary political race could make. In this case, proponents of the justice motive argue that fairness is served by the mere presentation of a second least expected outcome (i.e., the winning of the underdog), which makes the difference. After all, it was Melvin Lerner himself who called his brainchild “a fundamental delusion” (Lerner, 1980).

\section{Utilitarian-Based Motivations}

Another competing explanation for the support that non-partisan observers extend to the underdog may derive from a rather opposite motivation. Instead of seeking justice and trying to even the odds, onlookers may be guided by a rational, utilitarian standpoint. From this perspective, the choice of parties for whom to root follows a cold, rational calculation in terms of who will provide the biggest positive emotional payoff. This calculation is determined by expectation for success and predicted emotional payoff if successful.

If the underdog concept is based on expectations, non-partisan observers have little to lose by supporting the underdog. Losing is expected and thus does not carry any significant adverse implications, whereas winning could carry favorable consequences by its mere unexpectedness. On the other hand, if support is extended to the top dog, people stand to lose more. Winning is expected and thus bears smaller positive emotional benefits, while losing, because it is unexpected, could be devastating. A famous 
coaching mantra states: "winning is just staying alive, losing is dying." Underlying this thought process is a cost-benefit analysis to determine one's alignments with one of the competing sides. Steve Spurrier, once a football coach at the University of Florida, was quoted after many years of success: "I'd like to be the underdog again. ...Being an underdog is a little bit more fun at times...It's almost a disgrace every time we lose. It's a relief when we win instead of (the feeling) we got when we weren't supposed to.” (St. Petersburg Times, 1/8/ 2002). However convincing the utilitarian approach is, people tend to overestimate its use as a motive for behavior (Miller \& Ratner, 1998).

The affective consequences of expected and unexpected outcomes is well grounded in Decision Affect Theory (DAT; Shepperd \& McNulty, 2002), which postulates that human beings feel displeasure when their outcomes fall short of the counterfactual alternative and feel elated when their outcomes exceed the counterfactual alternative. In the present studies, expectations determine the counterfactual alternative. For example, Mellers and colleagues (Mellers, Schwartz, Ho, \& Ritov, 1997) found that experimental participants who took part in a series of gambles were overjoyed following unexpected wins compared to expected ones and, by contrast, were more disappointed after unexpected losses than expected ones. Shepperd and McNulty (2002) also found support for the theory in a less artificial experiment, in which expectations of high versus low risk in a fictitious medical condition were manipulated. Again, expectations influenced subsequent affect.

The intuitive logic of Decision Affect Theory can also be found in everyday expressions like “don’t get your hopes too high” and “expect the worse and you will never be disappointed.” It is, therefore, reasonable to predict that non-partisan observers 
adopt this rationale to protect themselves and use the utilitarian function of supporting the underdog to further their specific self-interests through which they can facilitate one's access to emotional resources. When adopting this perspective fully, one would assume that people are looking to get the best deal possible when extending their support to the underdog. Note that this motivation does not require people to identify or empathize with underdogs, nor does it require motives of justice to be elicited.

\section{Overview of the Present Studies and Hypotheses}

A series of four experiments was performed to explore the underdog phenomenon. The studies attempted to explore the conditions under which people supported underdogs, and whether such support was motivated by sympathy for the disadvantaged or pleasure in seeing the superior fall.

The first study sought to clarify the definition of an underdog and to explore the possible limits of supporting those in a competitive disadvantage. Past research has shown that people often support entities that have low expectations for success based on past histories of failure (e.g., Frazier \& Snyder, 1991; Markus, McGuire, Allison, \& Eylon, 2004). Study 1 attempted to replicate this finding and demonstrate conditions when this support eroded. Specifically, an important but unstudied qualifier of this effect involves the availability of resources: Whereas underdogs may typically be defined as entities with low probabilities for success, they may not enjoy support if they are perceived to have relatively prosperous resources. Thus, Study 1 tests the prediction that when past history of success or failure do not match relative resources (i.e., high resources/ long history of failure), the underdog effect diminishes, which qualifies 
resources as a moderator. The underdog effect was tested in the sports, political and business realms in an attempt to generalize the phenomenon. The resources-as-aqualifier hypothesis was tested only in the sports arena.

The second series of experiments (Studies 2-4) tested schadenfreude (i.e., taking pleasure in seeing the mighty fall) as a second, possibly competing explanation for the underdog effect. In Study 2, participants read vignettes about underdogs competing against top dogs. Half were asked about their emotions towards each team winning, while the other half were asked about their emotions toward each team losing. If people root for underdogs, the frame asking participants about the underdog winning should result in stronger ratings than the frame asking them about the top dog losing; however, if schadenfreude is operating, people's emotions should be stronger when responding to the top dog losing frame compared to the underdog winning. It was predicted that participants generally would support the underdog, but would reverse their course (taking greater pleasure in seeing the top dog lose than the underdog win) if the top dog's vast relative resources were made salient.

Study 3 used a “spoiler” scenario to test the schadenfreude hypothesis. In certain competitive situations, one side has nothing to gain or lose from a victory or loss, because one's fate has been determined (for example, a political candidate has no chance of winning an election, or a team has no hope of making a playoff). Still, these entities may be able to affect the destinies of others, by keeping them from winning important rewards (e.g., elections, playoffs). If our support for underdogs is driven solely by sympathy for them, the level of support should not change if the stakes change for the top dog. However, if we are motivated by schadenfreude, victories by underdogs should be 
particularly satisfying when they have the effect of punishing the top dog (e.g., costing a rival candidate the election; knocking the rival team from the playoffs). Study 3 tested this prediction by creating spoiler scenarios in which underdogs affected or did not affect important outcomes for the superior rival.

Study 4 tested the idea that people would direct more of their attention to a side for which they were rooting. To explore this, participants' memories of details from a video clip of a game were measured after the participants had read an underdog versus top dog scenario. It was predicted that participants would recall more details about the underdog than the top dog when the 'resources' component was missing (which would strengthen the underdog effect) but more details about the top dog when noticeable resource disparities were mentioned in the vignette (i.e., supporting a schadenfreude explanation). 
Study 1: Exploring the Underdog Construct

The goal of the first experiment was to replicate the little research supporting the tendency to root for underdogs, to expand the findings to 'real life' settings, and to establish boundary conditions for identifying and rooting for underdogs.

\section{Method}

\section{Participants.}

One hundred twenty eight undergraduate students participated in the first core sport study. The sample included 101 females (78.9\%), 17 males (13.3\%) and 10 who did not specify their gender (7.8\%).

One hundred and one undergraduate students participated in the second vignette sport study. The sample included 64 females (63.4\%), 22 males (21.8\%) and 15 who did not specify their gender (14.9\%).

Twenty two undergraduate students participated in the politics vignette study. The sample included 10 females (45.5\%), 6 males (27.3\%) and 6 who did not specify their gender (27.3\%).

Twenty three undergraduate students participated in the business vignette study. The sample included 10 females (43.5\%), 8 males (34.8\%) and 5 who did not specify their gender (21.7\%).

Students were recruited from large psychology undergraduate classes and the study was administered immediately following the lecture. Participants were awarded extra credit in exchange for their contribution to the study. 


\section{Procedure.}

Participants read scenarios about upcoming sports competitions. Participants were presented with two versions of stimuli: a core version which stated only the very basic data (Study 1a), and a vignette version similar to a newspaper article which included the core data as well as enriched background information to create a more naturalistic and involving scenario (Study 1b) (see Appendix A for materials). In each version, one party was described as more successful, while the other was described as the side with the least chances of winning. The description of the two teams was minimal in the core version. This allowed isolation of the effects of differing expectations on support tendencies. However, by removing any contextual narrative information, the scenarios were also somewhat removed from more realistic situations people are likely to encounter. For this reason, it was decided to also create a more naturalistic, detailed scenario that would more closely mirror commonly encountered competitions. Hence, in the naturalistic scenario version, participants read about the sports teams in a mock news article. By employing more detailed narrative encounters, a degree of face validity was gained, at the cost of a cleaner design with less extraneous variance. Together, the two versions provided a fairly clear indication of people’s motivational tendencies.

In each of the two studies, a manipulation was added to test whether the addition of information about relative resources could set boundaries to the support extended to underdogs. Crossing relative expectations and resources resulted in four scenario versions. Participants read a story a) pitting an expected winner against an expected loser, with no mention of resources; b) pitting a team with abundance of resources (where resources refer to players' salaries) vs. a team with limited resources; c) pitting a winner 
with high resources against a loser with low resources; or d) pitting a winner with low resources against a loser with high resources.

The participants then were asked to report which team they thought was going to win the match, who they supported and liked, which in their minds was the "underdog," and why (open ended; see Appendix A).

Across all scenarios, after completing the scenario questions, a questionnaire measuring social dominance orientation (Pratto, Sidanius, Stallwort, \& Malle, 1994) was administered to examine whether the tendency to support the underdog was embedded in a more comprehensive outlook about the world in general. The Social Dominance Orientation (SDO) scale measures the extent to which people desire (or oppose) hegemonic relationships between social groups (Pratto et al., 1994). Thus, SDO is positively associated with support for systems that help maintain hierarchical relationships between dominant and subordinate groups (e.g., military, law and order; Sidanius \& Pratto, 1999).

In addition, in Study 1b two news vignettes in the politics and business realms were explored in an attempt to generalize the phenomenon to other social domains. For each of these domains, we used only one version pitting a high versus low expectation rival (with no mention of relative resources).

In summary, Study 1 included four versions of a competitive sports scenario with varying information about two teams’ expectations for success and their relative resources: 1) low versus high expectations, 2) low vs. high resources, 3) low expectations plus low resources versus high expectations plus high resources, 4) low expectations plus high resources versus high expectations versus low resources. These conditions were 
manipulated in both a short, basic version and a more naturalistic news story version. In addition, two non-sports scenario contexts (business and politics) were added to test the robustness of the underdog effect across social domains.

Three predictions were made for this study. First, a general tendency to support underdogs compared to top dogs (as defined by history of success and failure and resources) was expected in all conditions. Second, when the expected loser had greater resources than the expected winner, support for the underdog was predicted to diminish. Third, the tendency to support underdogs was predicted to be attenuated for those participants who were high on social dominance orientation.

\section{Results - Study $1 a$}

Across all experiments in this thesis, a main dependent variable was the degree to which underdogs (versus top dogs) were supported. This was measured by asking how much participants wanted each team to win in an upcoming competition on 9-point Likert scales. In addition, underdog support was also explored through self-report of behavioral measures, such as which team a person would root for (a dichotomous measure). Who is going to win?

Across all three conditions where expectancies for winning were specifically stated, 92 out of 96 participants (96\%) stated that the team with the higher likelihood would eventually win, $\chi^{2}(1)=80.67, p<.001$. In the fourth, resources only condition, 28 out of 31 participants (90\%) predicted that the richer team would win, $\chi^{2}(1)=20.16$, $p<.001$ 
Who is the underdog?

Participants were asked which team they considered the underdog. Not surprisingly, when two teams with differing expectations for success were paired (with no mention of resources), almost everyone (97\%) thought the low expectations team was the underdog. Similarly, in the resources only condition, almost everyone (89\%) thought the team with the smaller payroll was the underdog. When the team with low expectations also had the smaller payroll, this team was also overwhelmingly chosen as the underdog (97\%). However, when the team with low expectations had the larger payroll, it was less likely to be seen as an underdog, as only $55 \%$ of participants rated it as such.

Which team would you like to win?

Overall, across all four conditions, the correlation between the support extended to Team $\mathrm{A}$ and Team B was negative, $r=-.63, p<.001$. Table 1 presents the mean ratings of desire for each team to win the game for each of the four conditions. In the condition pitting a team with low expectations versus a team with high expectations, the low expectation team was rated marginally higher $($ mean $=6.69)$ than the high expectation team $($ mean $=5.50, t(31)=1.85, p=.074)$. In the condition listing only the teams’ relative payrolls, the low resource team was rated significantly higher (mean = 6.88) than the high resource team (mean $=4.69, t(31)=4.17, p<.001)$. In the third condition, expectations for victory were paired with resources such that the team with the lower expectation also had a smaller payroll. In this condition the low expectations/low resources team was rated significantly higher $($ mean $=7.03)$ than the high expectations/high resources team $($ mean $=4.77 ; t(30)=3.69, p<.01)$. As hypothesized, 
there was a general tendency to support underdogs compared to top-dogs (as defined by expectations to win, lack of relative resources or both).

Most interesting was the condition in which resources did not match expectations for victory. Participants rated a team with low resources but high expectations significantly higher $($ mean $=5.97)$ than a team with high resources but low expectations (mean $=4.33, t(32)=2.62, p<.05)$. The results are even more extreme than predicted as the support completely reversed itself (the prediction was for diminished support for the low expectations team).

Table 1.

Desire for each team to win the game as a function of expectations for success and resources, Study $1 a$.

Degree of liking to win (1-9)

Team A

Team B

1) Team A: $70 \%$ chance of victory,

6.69

Team B: $30 \%$ chance of victory

2) Team A: high payroll,

$6.88 * *$

Team B: low payroll

3) Team A: 70\% chance of victory + high payroll, 4.77

Team B: $30 \%$ chance of victory + low payroll

4) Team A: 70\% chance of victory + low payroll, $\quad 5.97$

Team B: 30\% chance of victory + high payroll

Note. * Significant at the $\mathrm{p}<.05$ level. ${ }^{* *}$ Significant at the $\mathrm{p}<.001$ level. 


\section{Which team would you root for?}

When only expectancies are mentioned, half of the participants (16 out of 32) reported that they would root for the team with the lower likelihood of winning. When only resources were mentioned, 19 out of 31 (61\%) participants reported that they would root for the team with a smaller payroll, $\chi^{2}(1)=1.58, p>.05$. When resources matched likelihood of winning, 21 out of 31 participants (68\%) said that they would root for the lower likelihood of success/ lower resources team, $\chi^{2}(1)=3.90, p<.05$. All in all, in the three conditions where there was a clear disparity between the two teams (financial or expectancies of winning), 56 out of 94 participants (60\%) reported that they would root

for the lesser/weaker of the teams, $\chi^{2}(1)=3.45, p=.063$. However, in the fourth, nonmatching, condition, 26 out of 33 participants (79\%) reported that they would root for the team with the lesser resources but higher expectancy to win, $\chi^{2}(1)=10.94, p<.001$. Social dominance orientation.

Individuals high on social dominance orientation were hypothesized to be less likely to favor underdogs. To examine this relationship between social dominance orientation and team preference, the three versions where there was a clearly agreed upon underdog were examined. In each version, higher social dominance orientation scores correlated with lower support for the underdog relative to the top dog (rs were between .13 and -.30); however, the relationships failed to reach significance ( $p$ s $>.10)$. (Combining the three versions led to a marginally significant relationship, $r(95)=-.17, p$ $=.10)$. In the version pairing a team with high resources but low expectations against a team with low resources but high expectations, there was a trend such that participants with higher scores on social dominance scale were more favorable towards the team with 
high resources and low expectations, however the correlation was not significant $(r=.14$; $p>.10)$.

$$
\text { Results - Study 1b: Sports, Politics, and Business Vignettes }
$$

\section{Sports Vignettes}

Which team do you think is going to win? 72 out of 76 participants thought that the team with the better history of success (version 1-3) would win the upcoming match, $\chi^{2}(1)=60.84, p<.001$. When only resources were mentioned (version 4$), 19$ out of 25 participants thought that the team with the higher payroll would win, $\chi^{2}(1)=6.76, p=$ .009 .

Who is the underdog? Participants were asked which team they considered the underdog. Not surprisingly, when two teams with differing past histories of success were pitted against each other (with no mention of resources), 88\% thought the team with the lesser record was the underdog, $\chi^{2}(1)=14.44, p<.001$. Similarly, in the resources only condition, everyone (100\%) thought the team with the smaller payroll was the underdog. When the team with the lesser past success also had the smaller payroll, this team was also overwhelmingly chosen as the underdog $(88 \%), \chi^{2}(1)=14.44, p<.001$. However, when the team with the lesser record had the larger payroll, only $73 \%$ of participants rated it as such, $\chi^{2}(1)=4.55, p<.05$. Based on a contrast in proportions analysis the latter is significantly less than the previous three, $\mathrm{Z}=1.99, p<.05$.

Which team would you like to win? Table 2 presents the mean ratings of participants' stated desire for each team to win the game across the four conditions. Overall (across all four conditions), the correlation between the support extended to the two teams was negative, $r=-.55, p<.001$. 
In the condition pitting a team with a considerably better past history of success versus a team with a poor past history of success, the low success team was rated significantly higher (mean $=6.00$ on a 1-9 scale) than the better past history success team (mean $=4.40, t(24)=2.91, p=.05$ ), replicating the basic underdog effect. In the condition listing only the teams' relative payrolls, the low resource team was rated significantly higher $($ mean $=6.92)$ than the high resource team $($ mean $=4.24, t(24)=$ 4.09, $p<.001)$.

In the third condition, past history was paired with resources such that the team with the lesser past success also had a smaller payroll. In this condition the lesser success/low resources team was rated marginally significantly higher (mean =6.26) than the better record/ high resources team (mean $=4.89$ ), $t(26)=1.76, p=.09$. As hypothesized, there was a general tendency to support underdogs compared to top-dogs (as defined by past history of success/ failure, lack of relative resources or both). Most interesting was, again, the condition in which resources did not match history of success. When pairing a team with high resources but lesser past success $($ mean $=4.33$ ) against a team with low resources but better past record (mean $=6.29$ ), participants rated the latter significantly higher than the former $(t(23)=2.93, p<.05)$. The results are even more extreme than predicted as the support completely reversed itself (the hypothesis was of diminished support).

Which team would you root for? When only expectancies for winning were mentioned, $64 \%$ of the participants (16 out of 25 ) reported that they would root for the team with the lesser record, $\chi^{2}(1)=1.96, p>.05$. When only resources were mentioned, 18 out of 25 (72\%) participants reported that they would root for the team with a smaller 
payroll, $\chi^{2}(1)=4.84, p<.05$. When resources matched past record of wining, 15 out of 27 participants (56\%) said that they would root for the lower likelihood of success/ lower resources team, $\chi^{2}(1)=.33, p>.10$. All in all, in the three conditions where there were clear disparities between the two teams (financial or winning history), 49 out of 77 participants (64\%) reported that they would root for the lesser of the teams, $\chi^{2}(1)=5.73$, $\mathrm{p}=.017$. In the fourth, non-matching condition, 20 out of 23 participants (87\%) reported that they would root for the team with the lesser resources but better winning record, $\chi^{2}$ (1) $=12.57, p<.001$.

Social dominance orientation. Individuals high on social dominance orientation were expected to be less likely to favor underdogs. To examine the relationship between social dominance orientation and team preference in how much the participants wanted it to win (=difference score), a correlation analysis was performed. The correlation failed to reach significance or show any consistent pattern, $r(101)=0.04, \mathrm{p}>.05$. 
Table 2.

Desire for each team to win the game as a function of past history of success and resources, Study $1 b$.

Degree of liking to win (1-9)

Team A Team B
1) Team A: 29 wins against team $B$,
6.00
$4.40 *$
Team B: 70 wins against team A
6.92
$4.24 * *$
2) Team A: low payroll,
Team B: high payroll
3) Team A: 29 wins against team B + low payroll,
Team B: 70 wins against team A + high payroll
6.26
4.89
4) Team A: 29 wins against team $B+$ high payroll,
4.33
$6.29 *$
Team B: 70 wins against team A + low payroll

Note. * Significant at the $\mathrm{p}<.05$ level. ** Significant at the $\mathrm{p}<.001$ level.

\section{Political Vignette}

Which candidate is going to win the elections? Participants were presented with only one condition (counterbalanced) in which a seasoned incumbent was facing a newcomer in a congressional race. Twenty out of 22 participants (91\%) thought that the incumbent would win the elections, $\chi^{2}(1)=14.73, p<.001$.

Who is the underdog? Participants were also asked which candidate they considered the underdog. Not surprisingly, 95\% (19 out of 20) thought the newcomer was the underdog, $\chi^{2}(1)=16.20, p<.001$. 
Who would you like to win? Overall, the correlation between the support extended to the two competing candidates in the elections was negative, $\mathrm{r}=-.54, p<.05$. When pairing the incumbent $($ mean $=5.09)$ against the newcomer $($ mean $=5.14)$, there was no significant difference in how much participants wanted them to win $(t(21)=0.71$, $p>.05$ ). Contrary to the hypothesis, there was no tendency to support the candidate, who was in disadvantage prior to an upcoming race.

For whom would you vote? 59\% of the participants (13 out of 22) reported that they would vote for the incumbent, $\chi^{2}(1)=.727, p>.05$.

Social dominance orientation. Individuals high on social dominance orientation were expected to be less likely to favor underdogs. The hypothesis was not supported, as the correlation between the two did not reach significance: $r(22)=.124, p>.05$.

\section{Business Vignette}

Which restaurant do you think is going to do better, financially, in the future? Participants were presented with only one condition (counterbalanced) in which chain restaurants now captured the lion share of the market in the USA. 17 out of 23 (74\%) participants thought that the chain would do better in the future, $\chi^{2}(1)=5.26, p<.05$.

Who is the underdog? Participants were also asked which restaurant they considered the underdog. Not surprisingly, 73\% thought the mom-and-pop restaurant was the underdog, $\chi^{2}(1)=4.55, p<.05$.

Who would you like to succeed? Overall, the correlation between the support extended to the two entities in the competition was negative, $\mathrm{r}=-.48, p<.05$. When pairing a mom-and-pop venue (mean $=7.00$ ) against a chain (mean $=5.52$ ), participants rated the former marginally significantly higher than the latter regarding how much they 
would like to see it succeed in the future $(t(23)=2.00, p=.059)$. As hypothesized, there was a tendency to support the entity in relative deprivation in a competition.

Where would you dine? $57 \%$ of the participants (13 out of 23) reported that they would dine in the mom-and-pop restaurant, $\chi^{2}(1)=.39, p>.05$.

Social dominance orientation. Individuals high on social dominance orientation were expected to be less likely to favor underdogs. This hypothesis was not supported, as the correlation between the two did not reach significance $r(23)=-.08, p>.05$.

\section{Discussion}

In general, as hypothesized, people wished teams to win more when they were in a state of relative deprivation on some facet in comparison to a competitor. Teams with lower expectations for winning, unsuccessful histories of winning against another team, or with relatively small resources (or a combination of the first two with the latter) were supported significantly more than the superior teams they were facing in hypothetical matches. These findings are in line with past research (Frazier \& Snyder, 1991) and were substantiated both in a basic minimal scenario and in more realistic newspaper articles. Also, there was consensus among participants that the team with the relative disadvantage was considered the 'underdog,' no matter how this disadvantage was characterized (i.e., resources, chances of winning or past success). Support for the underdog was more mixed on a behavioral measure, which required people to choose for which team they would root.

Perhaps most interesting, in one condition two elements of disadvantage were pitted against each other. Specifically, teams which had lower expectations to win but possessed greater resources had their 'underdog' designation called into question by the 
participants. Thus, in this situation, there was much less consensus about whether these teams were even considered underdogs, as only 55\% of participants labeled them as such in the first study and 73\% in the second, despite their low expectations for success or history of failure. This is a sharp decline from the average of 93\% classification of being an underdog when experiencing a clear disadvantage in all other conditions. Moreover, in this condition there was a significant shift of support towards the team with fewer resources but the better chance of winning or history of success in the past.

In short, although entities given a low chance of success or having a past history of failure are generally considered underdogs, if an entity has a great deal of resources, they may nonetheless lose the underdog status and support. These results suggest that an underdog is not defined simply by expectations for success. The findings imply that justice might be a primary motivation underlying the underdog effect. That is, people seem to support underdogs because they are perceived as having less than their opponents, and people are motivated to see this disparity overcome. When those with low expectations have ample resources, it is much less clear where the injustice lies, or if an injustice even exists. In fact, sympathies seemed to be driven more by resource disparity than expectations.

The basic support for the underdog was generalized to two competing entities in the business world but failed to manifest itself in the world of politics were the challenger (lesser history of success) was not liked to win more than the incumbent. 


\section{Studies 2-4: Underdog or Schadenfreude?}

Assuming people do report greater support for underdogs, the next studies explored the psychology behind such support. People could support the weaker side out of some type of emotional connection, but alternatively, support may be driven more by the passive joy in the fall of grace of others. Thus, studies 2 through 4 attempted to determine which is the primary force: schadenfreude or support for the underdog. 


\section{Study 2: Framing Competitions as Desire to See Win or Lose}

\section{Method}

\section{Participants.}

One hundred and nineteen undergraduate students participated in the framing study. The sample included 80 females (67.2\%), 24 males (20.2\%) and 15 who did not specify their gender (12.6\%).

Students were recruited from large psychology undergraduate classes and the study was administered immediately following the lecture. Participants were awarded extra credit in exchange for their contribution to the study. Procedure.

A scenario of a team with high expectations for success and high resources versus a team with low expectations for success and low resources preparing for an upcoming minor league baseball contest was presented. An alternate version presented a top dog vs. an underdog with no mentioning of resources. After reading about the future competition, participants reported whom they supported. A framing manipulation measured the strength of people's emotional reactions to each team. Specifically, half of the participants were asked how much they wanted to see each team win (on a 9-point scale), and their level of support. The other half was asked how much they want to see each team lose (on a 9-point scale) and their level of support (see Appendix B for materials). If we primarily root for the underdog, responses to the win-frame should be stronger than responses to the lose-frame; however, if we are primarily driven by 
schadenfreude, responses to the lose-frame should be stronger than responses to the winframe. In summary, Study 2 employed a 2 (resources vs. no mention of resources) by 2 (win vs. lose questionnaire frame) between subject design.

It was hypothesized that when resources were not mentioned, participants' wishing for the underdog to win would be stronger than their aspiration for the top dog to fail. In addition, it was predicted that this course would reverse itself when the resources disparities were made salient. To measure strength of responses to each frame, responses of "How much would you like (the underdog) to win the game?" were compared to "How much would you like (the top dog) to lose the game?”

\section{Results}

In order to test the prediction that support for underdogs would be greater than rooting against top dogs unless resources disparities were made salient (in which case people would root more strongly against top dogs than they would for underdogs), a 2 (win frame versus lose frame) x 2 (resources mentioned or not) analysis of variance was conducted on desire to see each team win or lose.

A two-way ANOVA revealed a main effect of frame (underdog-win or top doglose) on how participants wanted a team to fare in the upcoming game, $F(1,115)=11.37$, $p=.001$. In particular, participants who were asked how much they wanted the underdog to win gave significantly higher ratings (mean $=6.68$ ) than participants who were asked about how much they wanted to top-dog to lose (mean $=5.35$ ). There was no main effect of resources on how much participants wanted each team to succeed in the game, $F(1,115)=.46, \mathrm{p}>.05$. There was also no interaction between framing and resources on how much participants wanted each team to fare in the game, $F(1,115)=0.72, \mathrm{p}>.05$. 
Individuals high on social dominance orientation were expected to be less likely to favor underdogs. However, high social dominance orientation scores did not correlate with lower support for the underdog relative to the top dog, $r(119)=.007, p>.05$.

\section{Discussion}

In the second experiment, an attempt was made to establish whether the support extended to the underdog is really an emotional alignment with the disadvantaged side, or is driven more by opposition to the top dog, a phenomenon termed in the literature and philosophy as schadenfreude.

Framing the questions as either win ('How much would you like each team to win?') or lose ('How much would you like each team to lose?') yielded significantly more rooting for underdogs than rooting against top dogs. However, there was no influence of resources on the emotional reaction of the participants to the two entities as was predicted by the stated hypothesis.

The results are consistent with the theory that underdog support is driven by sympathy for the disadvantaged rather than disdain for the advantaged. However, the greater degree of rooting for, rather than against, teams may be confounded with social desirability biases. Specifically, participants may have curbed their responses, as it may be less acceptable to show opposition than to demonstrate support. Thus, the interplay between schadenfreude and underdog support requires further inquiry under a different research design, as described below. 
Study 3: The Role of the Spoiler

Study 3 tested schadenfreude versus underdog using a 'spoiler' paradigm. In the world of sports (and politics), a spoiler is a team that cannot gain anything by winning a game (beyond the spirit of true sport), but can determine the fate of its adversarial top dog (e.g., preventing it from making the playoffs). Elevated levels of support for the underdog in this particular case may further lend credibility to the schadenfreude explanation. The hypothesis suggested that, in essence, participants increase their level of support for the underdog in the spoiler setting. Note that if participants do particularly support underdogs when they play the role of spoiler, it would lend support to the idea that justice motivates the underdog effect, and it would argue against a simple utilitarian explanation (as expectations for success do not change).

\section{Method}

\section{Participants.}

One hundred undergraduate students participated in the spoiler study. The sample included 63 females, 19 males and 18 who did not specify their gender.

Students were recruited from large psychology undergraduate classes and the study was administered immediately following the lecture. Participants were awarded extra credit in exchange for their contribution in the study.

\section{Procedure.}

Participants read a brief scenario of an underdog versus a top dog high school sports rivalry and indicated their level of support for each team. In control versions of 
the scenario, the contest was described as having equal stakes for both teams (but not equal strength); in the experimental condition, the underdog was described as being a potential "spoiler," in that the team was be able to eliminate its rival from the playoffs with a victory (see Appendix C for materials). Study 3 is, thus, a 2 (spoiler vs. no spoiler) by 2 (resource vs. no mention of resources) between subjects design. It was predicted that this spoiler manipulation would not affect the degree to which participants root for the underdog, unless major resource disparities were made salient. When resources were made salient, it was predicted that participants would root more strongly for the underdog, compared to the non-spoiler condition.

\section{Results}

Which team do you think is going to win?

84 out of 100 participants thought that the team with the better history of success would win the upcoming match, $\chi^{2}(1)=46.24, p<.001$. Who is the underdog?

Not surprisingly, 80 out of 91 participants identified the team with the lesser record as the underdog, $\chi^{2}(1)=52.32, p<.001$. Which team would you like to win?

Overall, the correlation between the participants ratings of how much they wanted each team to win (1-9 scale) was negative, $r=-.60, p<.001$. A 2 (underdog/top dog status) x 2 (spoiler vs. non-spoiler) x 2 (resources) mixed-model ANOVA was performed to test the prediction that people would favor an underdog over a top dog; that favoritism would increase if the underdog played the role of spoiler and if resource disparities were made salient, but would not increase if they were not made salient. As predicted, there 
was a significant main effect of underdog/ top-dog status (within factor) on how much participants wanted each team to win: $F(1,96)=18.48, p<.001$. Specifically, underdogs were supported significantly more $(M=6.4)$ than top dogs $(M=4.76)$. There were no significant main effects for underdog role (spoiler vs. non-spoiler, between factor) or resources (present or absent, between factor). The predicted interaction between the support extended to each team and the scenario approached significance, $F(1,96)=3.28$, $p=.073$, but in a direction contrary to the hypothesis, such that underdog support $(\mathrm{M}=$ 6.78) diminished under a spoiler scenario $(M=6.02)$, while top-dog support increased from a non-spoiler scenario $(M=4.42)$ to a spoiler scenario $(M=5.10$; see Figure 1$)$. Stated differently, being a spoiler did not boost the support for the underdog and, hence, support for schadenfreude was not evident.

Which team would you root for?

Across all conditions, 68\% (68 out of 100) participants reported that they would root for the team with the lesser record, $\chi^{2}(1)=12.96, p<.001$. In the non-spoiler scenario $74 \%$ (37 out of 50) supported the underdog, $\chi^{2}(1)=11.5, p<.001$. The support for the team with the lesser record diminished (31 out of 50, or 62\%) and was no longer significant in the spoiler scenario, $\chi^{2}(1)=2.88, p=.09$. Also, the addition of resources played a role in which team the participants supported: When resources were mentioned, $74 \%$ of the participants (40 out of 54) reported that they would root for the team with the lesser record, $\chi^{2}(1)=12.52, p<.001$. However, when resources were omitted, only $61 \%$ of the participants (28 out of 46) reported that they would root for the team with the lesser record, $\chi^{2}(1)=2.17, p>.05$. 


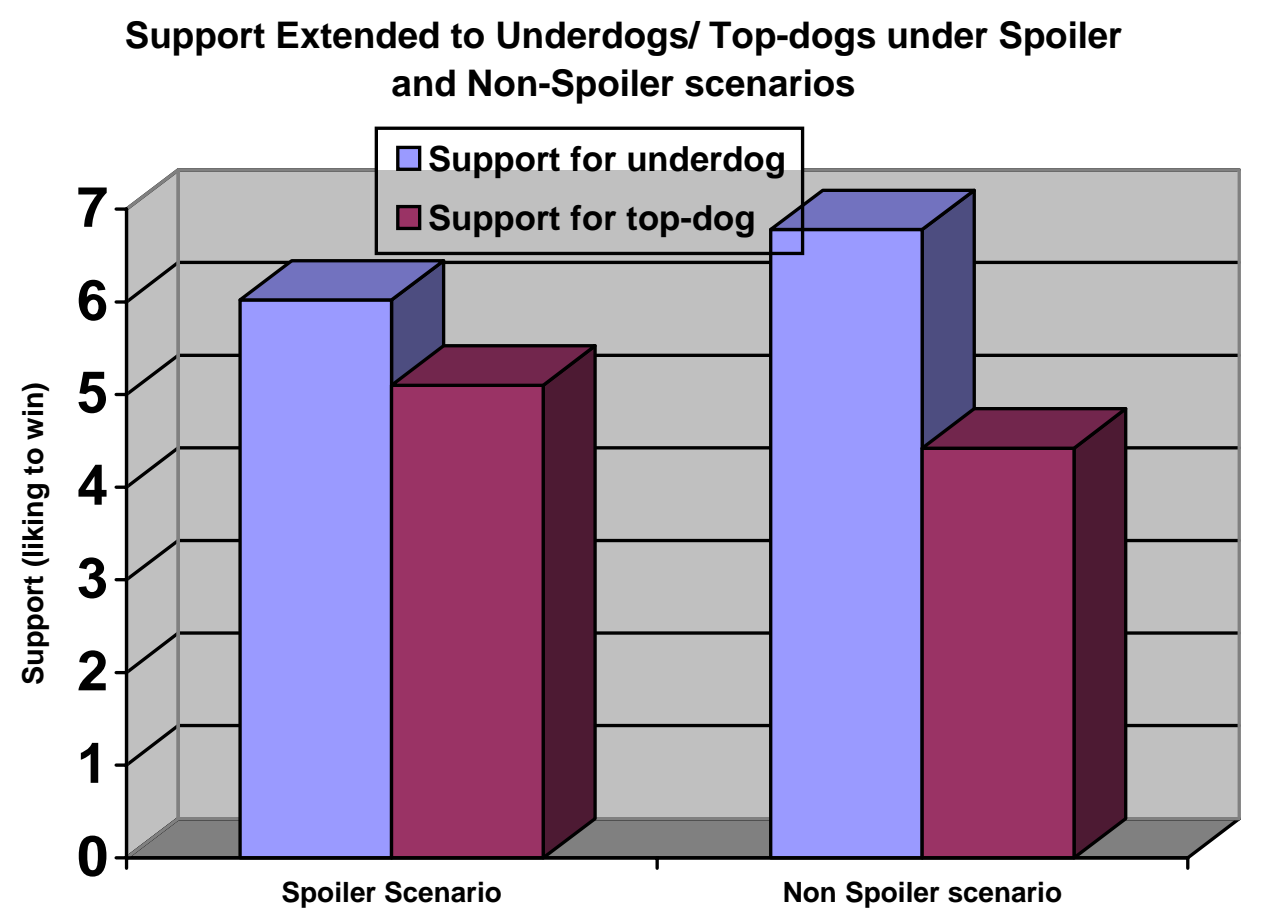

Figure 1. Support extended to underdogs/ top dogs under spoiler and non-spoiler scenarios, Study 3.

Social dominance orientation.

Individuals high on social dominance orientation were expected to be less likely to favor underdogs. Indeed, higher social dominance orientation scores correlated with lower support for the underdog relative to the top dog, $r(100)=-.22, p=.032$. This relationship was even stronger when resources were added to the vignette, $r(54)=-.30, p$ $=.027$. 


\section{Discussion}

In order to investigate whether schadenfreude (rooting against the top dog) was a driving force behind underdog support, the concept of a 'spoiler' was introduced into the design. It was assumed that if the underdog was supported more when it could spoil (hence a 'spoiler') the future of the top dog but gain very little for itself by doing so, this would be evidence of schadenfreude. Alternatively, if support for the underdog remained the same, whether or not it was a spoiler, then one could deduct that rooting against the top dog does not play a major role in the underdog phenomenon.

As was the case in all previous experiments, underdogs were supported significantly more than top dogs, regardless of resources being mentioned or not and the presence or absence of a spoiler scenario. It was predicted that underdog support would be affected by the mentioning of a resource disparity. More specifically, if resources disparities were made salient under the spoiler scenario, rooting against the top dog would increase, but if they were not mentioned, then only rooting for the underdog would increase. However, in the spoiler condition the support for the underdog diminished while the support for the top-dog increased regardless of whether resources were mentioned or not, contrary to the schadenfreude hypothesis. It appears that when the top dog is about to lose something of real value, participants are less inclined to support its lesser adversary.

Social dominance orientation also correlated with the tendency to support the underdog, as predicted. Note, however, that this relationship failed to emerge in the other studies, so this result should be taken with caution. 


\section{Study 4: Attentional Focus While Observing a Competition}

Although Study 2 provided evidence for people’s underlying motivations, one could yet not rule out the possibility that differences in extremity of responses across framing conditions resulted from social desirability concerns (that is, people may in fact respond more extremely to win frames than lose frames because it may seem meanspirited to desire someone’s defeat). Study 3 helped minimize this concern, as people may have felt fairly comfortable rooting for underdogs who were considered spoilers. Still, social desirability concerns may temper self-reported support for underdogs (or against top dogs). Consequently, Study 4 was designed in an attempt to bypass social desirability concerns in "schadenfreude” versus “underdog” phenomena by testing memory for events in addition to support tendencies.

\section{Method}

\section{Participants.}

One hundred and thirty three undergraduate students participated in the attentional focus study. The sample included 96 females (72.2\%), 31 males (23.3\%) and 6 who did not specify their gender (4.5\%).

Students were recruited through an online departmental recruiting site (experimentrak). Participants were awarded extra credit in exchange for their contribution in the study. 


\section{Procedure.}

Participants read a short vignette describing the history of two European pro basketball teams’ rivalry, with an underdog and a top dog (the team described as the underdog was counterbalanced across participants). The two teams were described as competing in an important upcoming championship game. After reading about the background rivalry between the two team, participants were asked to report which team they supported and which team was the underdog (see Appendix D for materials). Immediately following this, they watched a short video clip of the supposed game between the two teams. At the conclusion of the 10-minute clip, the participants were asked to recall names, uniform colors and the country/ city the teams represented. Additionally, following the free recall stage, the participants were asked to recognize them out of a list (forced choice). These recall and recognition measures (see Appendix D for materials) were used to explore whether the participants focused their attention on either the underdog or top dog, which served as an implicit measure of the underdog effect. Study 4 is, thus, a 2 (top dog versus underdog, counterbalanced) by 2 (resources versus no mention of resources) mixed subjects design.

It was predicted that participants would attend more closely to the underdog (i.e., remember more details about the underdog team) when no resources were mentioned; however, similar to Study 1, when a disparity in resources became apparent, participants were expected to shift their focus of attention from the underdog to the top dog, as schadenfreude became a driving emotion. 


\section{Results}

Before watching the video clip, participants read a vignette aimed to prime them to the underdog/top dog nature of the two competing basketball teams. They then completed a brief pre-video questionnaire. Immediately after watching the clip, the participants answered a second memory questionnaire. 8 out of 133 participants were excluded from the analysis, because they incorrectly identified the top dog as the underdog, immediately following reading the introductory vignette (i.e., failed the manipulation check). Pre-video underdog support.

Prior to watching the game, 103 out of 125 individuals (82 \%) thought that the top dog would win the game, $\chi^{2}(1)=52.76, p<.001$.

Which team would you like to win?

Taking the previous history of success into account, the average support for the underdog was 6.85 while the average support for the top dog was 3.83. A 2 (underdog/top dog status) x 2 (resources) mixed-model ANOVA was performed. Three was a main effect for support, $\mathrm{F}(1,123)=78.42, \mathrm{p}<.001$. There was no main effect for resources, $F(1,123)=.30, p>.05$. There was also no interaction of support and resources, contrary to the initial hypothesis, $F(1,123)=.18, p>.05$.

Which team would you root for?

Ninety out of 125 (72 \%) participants reported that, not knowing anything else, they would probably root for the underdog, $\chi^{2}(1)=24.07, p<.001$. 
Memory (post video watching): Recall.

Initially there were 4 separate recall questions. The fourth item ("What numbers of jerseys do you recall?”) was eliminated because most participants mentioned the number without specifying to which team it belonged to. The three other questions were combined together into an aggregate recall variable, to have a sufficient range of responses (there were 3, 2, and 16 possible items for questions 1,2 and 3 respectively) to avoid ceiling or floor effects.

First, a paired sample $t$-tests were conducted to assess if information about either of the teams was recalled significantly better, regardless of underdog/top dog status. The analyses revealed that participants recalled significantly more information about Maccabi Tel-Aviv (the local team, $\mathrm{M}=4.12$ ) than CSKA Moscow $(\mathrm{M}=3.7), t(124)=3.43, p=$ .001. However, using a paired sample $t$-test, the number of recalled items for the underdog $(\mathrm{M}=3.98)$ did not differ significantly from the top $\operatorname{dog}(\mathrm{M}=3.85), t(124)=$ $1.01, p>.05$. The addition of the resources component did not yield an interaction, $F$ (1, $123)=.19, p>.05$, nor did it produce a main effect, $F(1,123)=.61, p>.05$. Memory (post video watching): Recognition.

There was a significant difference in recognition of players between the two teams, with Maccabi (the home team) players being recognized more $(\mathrm{M}=70 \%)$ than CSKA players $(\mathrm{M}=60 \%), t(122)=5.42, p<.001$. Taking into account the underdog/top dog manipulation, participants' recognition was significantly better than chance both when they were asked about the underdog $(\mathrm{M}=65 \%,(t(122)=8.88, p<.01)$ and when inquired about the top $\operatorname{dog}(\mathrm{M}=66 \%, t(123)=9.37, p<.01)$. However, based on the results of a paired $t$-test results, there was no difference in the recognition for the 
underdog as opposed to the top dog, $t(121)=-.52, p>.05$. The addition of resources to the analysis produced a significant interaction $(F(1,120)=4.07, p=.046)$ but in the direction contrary to the hypothesis: As shown in Figure 2, there was a better recognition for players of the stated underdog (66\%) than the top-dog (63\%) under the resourcesmentioned condition, while the reverse was detected when resources were not mentioned (63\% underdog recognition vs. 68\% top dog recognition).

In the jersey numbers recognition task, there was no significant difference between the two teams (without under/top dog manipulation), $t(122)=-1.12, p>.05$. Participants were able to remember significantly better than chance only for the top dog condition $(\mathrm{M}=58 \%), t(122)=4.56, p<.001$, while their recognition was no different from chance when they were asked about the underdog $(\mathrm{M}=52 \%), t(122)=1.08, p=$ .282. This difference (Mean Difference $=.06$ ) was significant, $t(122)=2.31, p=.02$. The addition of resources did not change this trend as was hypothesized, $F(1,121)=$ $.002, p>.05$.

When asked to recognize the final score (after watching the clip) out of a four choice options, 110 out of 124 participants (89\%) recognized the correct score, $\chi^{2}(3)=$ 268.58, $p<.001$. Due to the high correct response rate, the inclusion of resources exerted no influence over recognition.

Exploratory analyses about attributions for performance.

In addition to the memory data, an attempt was made also to assess whether the support for the underdog was influenced by attributions of superior effort compensating, supposedly, for lack of talent. Participants were questioned about hustle, heart and effort as opposed to natural ability and on-court intelligence of each team. Underdogs were 
perceived to exert significantly more effort (aggregating hustle, heart, and effort questions) ( $\mathrm{M}=4.39$ out of 5$)$ than top dogs $(\mathrm{M}=4.01, \mathrm{t}(75)=3.57, p<.05)$. However, top-dogs $(\mathrm{M}=4.03)$ were judged to possess significantly more ability (aggregating natural ability and on-court intelligence) than underdogs $(\mathrm{M}=3.74), \mathrm{t}(75)=-2.93, p<.05$. The addition of resource disparity had a main effect so that both teams were judged to be trying harder, $\mathrm{F}(1,74)=6.86, p<.05$.

\section{Percentage of Recognition of Underdog/ Top-dog players when Resources are present and not}

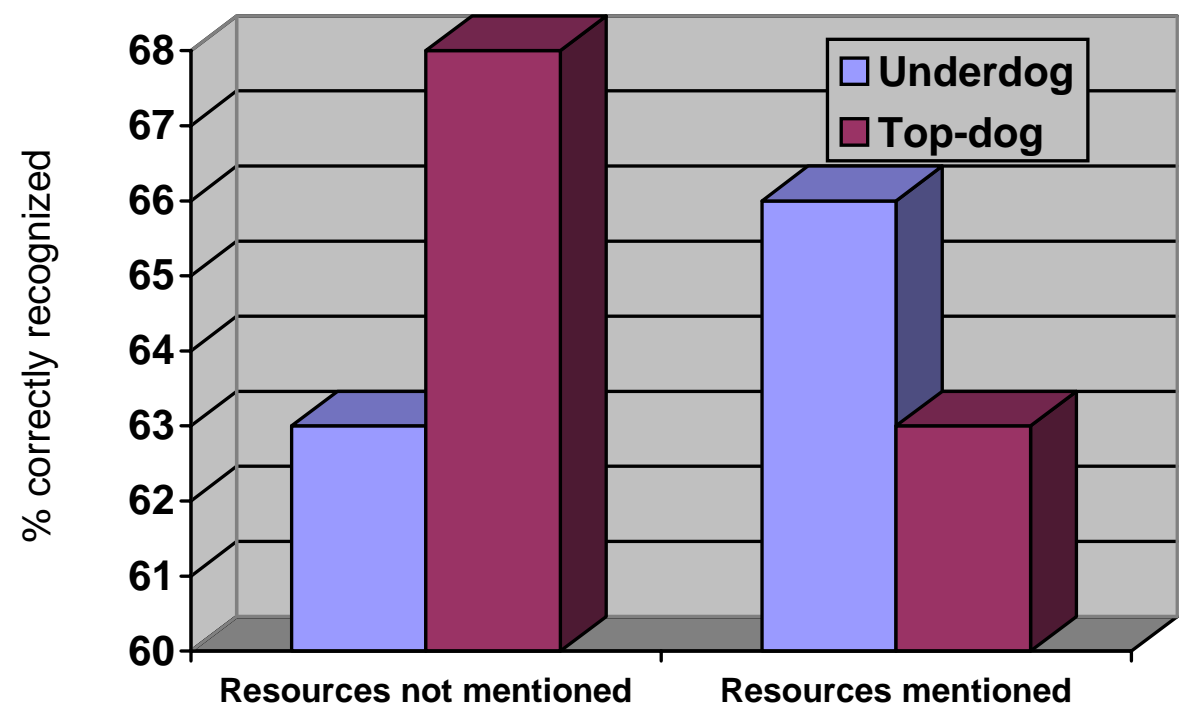

Figure 2. Percentage of recognition of underdog/top dog players when resources are present or not, Study 4. 


\section{Discussion}

The last study, which focused on underdog support vs. schadenfreude, shifted the inquiry from direct responses of how much the participants aligned themselves with either of the parties involved to the more basic question of how much information they remembered about each team. The basic premise was that if participants remembered more details about one of the two entities, then their focus of attention should lead us to a better understanding of the underlying driving forces, such that if participants remembered more about the underdog, they were in essence rooting for it and alternatively, if they remembered more about the top dog, they were focused on rooting against it. Also, by focusing on memory, it was believed that social desirability concerns would be circumvented. The predictions stated that memory for the underdog would be superior overall, but that this course would be reversed when resources disparity was made salient, thus shifting participants locus of attention to the top dog and possibly signifying a shift to schadenfreude.

Overall, memory results were weak. In the free recall test, there were no differences as to how much participants remembered about the two teams. In the first recognition task participants were asked to identify names of players from each team. There was, again, no difference between memory shown to either underdogs or top dogs (recognition overall was significantly better than chance). However, there was an interaction between disparity of resources and underdog status such that better memory towards the top dog was exhibited when resources were not present while better recognition for the underdog was demonstrated when resource disparity was mentioned. In the second recognition task participants were asked to assign a player to a jersey 
number out of two possible options. Recognition for the top dog was significantly better than for the underdog which was, in turn, no different from chance. This better recognition was demonstrated regardless of disparity of resources. This finding is valuable as it may signify participants' focus of attention in a task over which they had the least conscious control (indeed many of them reported to the researchers that they were merely guessing as they had no clear recollection of any jersey number).

In addition, an exploratory examination as to the attributions people make about performance demonstrated that participants attributed more effort to the underdog and more 'natural ability' to the top dog. This phenomenon of 'selective attribution style' was also demonstrated by Stone, Perry and Darley (1997) who had participants listen to a short segment of basketball game on the radio and led them to believe that the player they were following was either black or white. The participants made their attributions according to race: If they thought the target was an African-American, they attributed his performance to natural ability, but if they thought the player to be white, they attributed his performance to hustle and hard work. It is important to note that the participants recalled a similar amount of 'objective' information about the player (i.e., points, assists, rebounds, etc.) regardless of the race to which they thought he belonged. Wann et al. (2002) demonstrated that participants tended to like athletes whose performance they deemed largely to be the result of hard work, as opposed to naturally talented athletes. This suggests that one possible reason as to why underdogs are supported is because it is believed that they try harder than those with more ability. 


\section{General Discussion}

Overall, across all four experiments strong evidence was found for the support extended to underdogs in comparison to top dogs. Whenever an entity was clearly marked as an inferior to its adversary, the participants demonstrated their liking for the former to overcome its mightier adversary. In conditions where there was some inconsistency in the nature of the disparity (e.g., fewer resources but higher expectations), resources (money in this case) seemed to have a stronger influence on support than did mere expectations for performance.

This finding is important because it sheds light on the motivations behind underdog support. It appears that the participants may be motivated to believe the world is a just place (Lerner, 1975, 1977) by supporting the weaker entity. The most telling are, of course, scenarios in which disparities in expectations do not match disparities in resources. Skitka and Tetlock’s (1992) contingency model of resource distribution seems relevant here. They propose that after an allocator of resources makes a determination that a situation of insufficiency exists, she or he turns to attributional analysis. The question then is: are the claimants personally responsible for their predicament or not? In our case, participants need to make up their minds whom to support in a competition. Though one team is in a definite disadvantageous position when it comes to its expectations to win, the participant, based on resource availability, can assess whether it had been negligent in managing its affairs (i.e., personally responsible according to the model) or just unfortunate. It appears that case in the non-matching scenarios the former 
(i.e., personal negligence/responsibility) is presumed and, as a result, the support is taken away and the underdog status becomes less obvious.

The 'justice at the core' of underdog support is both interesting and consistent with the present results, but does not completely rule out other motivations such as a utilitarian motivation. From this perspective, the choice of parties for whom to root follows a cold, rational calculation as to which party would provide the biggest positive emotional payoff. This calculation is determined by expectation for success and predicted emotional payoff, if successful.

If the underdog concept is based on expectations, non-partisan observers have little to lose by supporting the underdog. Losing is expected and thus does not carry any significant adverse implications, whereas winning could carry favorable consequences by its mere unexpectedness. On the other hand, if support is extended to the top dog, people stand to lose more. Winning is expected and thus bears smaller positive emotional benefits, while losing, because of its unexpectedness, could be devastating. Although if this was the underlying motivation, one should not have observed the marked shift in support and underdog designation in the non-matching scenarios as expectations did not change.

In this regard, the spoiler study also makes an important contribution. The results of this study were such that participants did not show an increase of support towards underdogs when they assumed the position of spoilers. If they had done so, one could have argued for support for the utilitarian motivation, as the stakes are now higher for the top dog (its future is on the line) though the expectations are much the same. Thus, two 
indirect measures in support of the social fairness argument over the utilitarian motivation were obtained.

One qualification for the underdog phenomenon is the politics domain, in which the phenomenon was not evident. It may perfectly be the case that when participants deem the situation relevant-proximal (voting in an election) and exerting a subjectively important and somewhat influential role, they avoid showing these tendencies. In other words, a tenured professor, for example, will be less likely to favor the hiring of an underdog as an assistant professor over a top dog at a neighboring university because of the indirect influence this hiring will have over her in the future. This distinction needs further study as the underdog support was exhibited not only in sports, which is a rather natural domain in which the observers exert almost no influence over the score (unless one believes that rooting hard makes a real difference), but also in the business domain where shoppers spend their money and by doing so influence the viability of commercial entities.

The second focus of the study was to identify if the underdog phenomenon is driven by support for the disadvantaged or in essence represents a mirror image of it: rooting against the top dog (schadenfreude). Here the findings are less consistent and open to more than one interpretation.

In the second study questions were framed about how much participants wanted the underdog to win, compared to how much they wanted a top dog to lose. This design was intended to overcome the high negative correlations between the support that participants extend to two entities in a direct competition, which suggest a possible nonindependence of responses (i.e., one cannot support one entity without rooting against the 
other). It was found that participants were more extreme in supporting the underdog than rooting against the top dog, providing no evidence for schadenfreude. This finding, however, did not provide conclusive evidence that sympathy for underdogs is the primary driving force behind their support, because participants might have felt pressure to respond in a socially desirable way (i.e., it may be seen as "impolite” or "rude” to report desiring to see someone lose).

In a second attempt to distinguish between motivations to root for underdogs versus root against top dogs, the concept of the spoiler was introduced. It was defined as an entity in a lesser position, able to adversely affect the future of the top dog but gain nothing for itself by doing so except for the mere pleasure of winning. In the spoiler experiment, if participants showed significantly more support for an underdog who was a spoiler, one could assume that this added support, all else being equal, is driven by schadenfreude. However, there was no increased support for underdogs under spoiler conditions, and in fact, if any, there was a tendency to support underdogs less when they played the spoiler role. In the fourth and last experiment, participants read a vignette about an underdog scenario and then watched a basketball game depicting the two teams they read about. It was hypothesized that if participants were driven by schadenfreude, they would focus their attention (and thus, their memory) on the advantaged team particularly when resource disparities were made salient. However, participants did not differ in their recall memory of the underdog and the top dog. They also did not differ in the first and easier recognition task (detecting a name of a player who took part in the game from a bogus one). 
Nevertheless differences were found in the third and most difficult recognition task (where participants were asked to attach a player name to the correct jersey number out of two possible options), showing a markedly better memory towards the top dog than the underdog. However, there was no interaction with the presence or absence of resources, as predicted. Overall, across the studies, there was little evidence that schadenfreude motivated people in these scenarios to support underdogs. Conversely, another mechanism, which may have mediated the underdog and support relationship, was established: The participants perceived the underdog team to exert significantly more effort and spirit than its superior counterpart, which was seen as more talented.

\section{Limitations}

This attempt to explore the underdog phenomenon was limited in a few respects. The first limitation is related to ecological validity: Even though a consistent effort was made to create realistic newspaper articles and to present the participants with a 'real' basketball clip, the realism factor might have been rather diminished compared to actual life situations where there can be real emotional stakes for supporting an entity, and emotional gravity is sometimes reinforced by social interactions. Secondly, social desirability, as manifested in more expressing approval to being in favor of something rather than against, might have served as another possible limitation to the current investigation. Although, one can argue that social desirability may not play a major role in the world of sports where fans are often not shy about making their hatred against power-house teams such as the Yankees and the Lakers well known. 
Another possible methodological limitation is the apparent dependence of judgments participants are making when they are called to assess two competing entities. The current investigation assumed that there are two distinct forces at work here: underdog support and schadenfreude, which pull in the same direction and thus are hard to distinguish from one another. Contrary to this idea, one can make the argument that these are interchangeable forces, which represent the same phenomenon, and by trying to separate them, we actually created an epiphenomenon rather than sort it out. Although, a counterargument can be made on both research and philosophical grounds, as the schadenfreude phenomenon is well documented in research (Ceci \& Kain, 1982; Feather, 1991; Feather \& Sherman, 2002) to be discounted as an epiphenomenon.

A more specific limitation is associated with the spoiler experiment only. The vignette for this experiment did not include any description of indirect benefits of the spoiler scenario, had the underdog succeeded. In reality, people usually have information about other entities besides the spoiler and its adversary, and these third party entities are invariably affected by the outcome of the contest. In our case, it may have caused our participants to shy away from supporting the spoiler as it seemed like a waste of resources (the top dog doesn't qualify for the playoffs, the underdog also does not qualify) as opposed to a non-spoiler scenario (the top dog qualifies, the underdog does not).

Finally, another limitation was of special concern for the memory study. Specifically, the clip at hand appeared to be skewed towards the home team (based on the participants' better memory performance for the home team, regardless of the 
experimental manipulation). Thus, future studies should assure that there are no memory biases indebted (e.g., a neutral ground game might be preferable).

\section{Future Directions}

As the underdog support seems to be a robust phenomenon exhibited by the majority of the participants but not all, it may be worthwhile to explore individual differences in this regard. Although the effort to link the underdog phenomenon to social dominance orientation failed, it might be worthwhile pursuing this line of investigation with other variables, such as demographic characteristics (e.g., social class, earnings), political leanings, or other personality variables (e.g., attribution style). Feather (1991), for instance, was able to establish that rooting against "tall poppies” (i.e., schadenfreude) was associated with low global self-esteem and low perceived self-competence among high school students.

Another potential avenue of exploration for the future is the cultural or international arena. Past research about underdogs (Ceci \& Kain, 1982; Frazier \& Snyder, 1991) was conducted when the US was not the lone superpower in terms of political sphere of influence, army buildup and economic power (before the complete dissemination of the Communist Block). Being the paragon top dog nowadays may immune the US citizen to the underdog phenomenon or at least attenuate its effects (the effect sizes we were detecting were below those of Frazier \& Snyder who explored the underdog phenomenon in the similar domain of sports with the same college age population in 1991). Thus, it seems warranted to explore the magnitude of the phenomenon in a larger geo-political context, across different countries, and to tie it with 
various external objective measures such as GDP, national debt, or relative size in comparison to neighboring countries.

All in all, underdog research seems to hold a significant potential for further investigation at many levels. The intuitive appeal that people feel towards underdogs and the basic repulsion in being in a disadvantageous position leaves fertile ground for further research, or as the former Bucs coach, the late John Mckay, put it: "Underdog, overdog, hotdog. I guess you want to be an underdog - but an underdog with the best team!”. 


\section{References}

Batson, C. D. (1987). Prosocial motivation: Is it ever truly altruistic? In L. Berkowitz, (Ed). Advances in experimental social psychology, Vol. 20 (pp. 65-122).

Bonta, B. D. (1997). Cooperation and competition in peaceful societies. Psychological Bulletin, 121, 299-320.

Brigham, N. L., Kelso, K. A., Jackson, M. A. \& Smith, R. H. (1997). The roles of invidious comparison and deservingness in sympathy and schadenfreude. Basic and Applied Social Psychology, 19, 363-380.

Carroll, J. S., Perkowitz, W. T., Lurigio, A. J., \& Weaver, F. M. (1987). Sentencing goals, causal attributions, ideology, and personality. Journal of Personality \& Social Psychology, 52, 107-118.

Cialdini, R. B., Borden, R. J., Thorne, A., Walker, M. R., Freeman, S., \& Sloan, L. R. (1976). Basking in reflected glory: Three (football) studies. Journal of Personality and Social Psychology, 34 366-375.

Ceci, S. J., \& Kain, E. L. (1982). Jumping on the bandwagon with the underdog: The impact of attitude polls on polling behavior. Public Opinion Quarterly, 46, 228242.

Cohen, J. (1992). A power primer. Psychological Bulletin, 112, 155-159.

Deutsch, M. (1975). Equity, equality, and need: What determines which values will be used as the basis for distributive justice? Journal of Social Issues, 31, 137-149. 
Deutsch, M. (1985). Distributive justice: A social-psychological perspective. New Haven, CT: Yale University Press.

End, C. M., Dietz-Uhler, B., Harrick, E. A., \& Jacquemotte, L. (2002). Identifying with winners: A reexamination of sport fans' tendency to BIRG. Journal of Applied Social Psychology, 32, 1017-1030.

Feather, N. T. (1991). Attitudes towards the high achievers: Effects of perceived own level of competence. Australian Journal of Psychology, 43, 121-124.

Feather, N. T., \& Sherman, R. (2002). Envy, resentment, schadenfreude, and sympathy: Reactions to deserved and undeserved achievement and subsequent failure. Personality and Social Psychology Bulletin, 28, 953-961.

Festinger, L. (1954). A theory of social comparison processes. Human Relations, 7, 117140.

Frazier, J. A., \& Snyder, E. E. (1991). The underdog concept in sport. Sociology of Sport Journal, 8, 380-388.

Hastorf, A. H., \& Cantril, H. (1954). They saw a game; a case study. Journal of Abnormal \& Social Psychology, 49, 129-134.

Heider, F. (1958). The psychology of interpersonal relations. New York: Wiley.

Hirt, E. R., Zillmann, D., Erickson, G. A., \& Kennedy, C. (1992). Costs and benefits of allegiance: Changes in fans’ self-ascribed competences after team victory versus defeat. Journal of Personality and Social Psychology, 63, 724-738.

Hogg, M. A., \& Abrams, D. (1988). Social identifications: A social psychology of intergroup relations and group processes. New York: Routledge. 
Hyper Dictionary Online (2004). Retrieved May 23, 2004, from http://www.hyperdictionary.com/search.aspx?define=underdog

Kinder, D. R. (1998). Opinion and action in the realm of politics. In D. T. Gilbert \& S. T. Fiske (Eds.), The handbook of social psychology, Vol. 2 (4th ed.) (pp. 778867).

Lazarus, R. S. (1982). Thoughts on the relations between emotion and cognition. American Psychologist, 37, 1019-1024.

Leach, C. W., Spears, R., Branscombe, N. R., \& Doosje, B. (2003). Malicious pleasure: Schadenfreude at the suffering of another group. Journal of Personality \& Social Psychology, 84, 932-943.

Lerner, M. J. (1975). The justice motive in social behavior: Introduction. Journal in Social Issues, 31, 1-19.

Lerner, M. J. (1977). The justice motive: Some hypotheses as to its origins and forms. Journal of Personality, 45, 1-52.

Lerner, M. J. (1980). The belief in a just world: A fundamental delusion. New York: Planum Press.

Lewin, K. (1951). Field theory in social science: Selected theoretical papers. New York: Harper \& Row.

Markus, M. J., McGuire, H. A., Allison, S., \& Eylon, D. (2004). Why people root for the underdog: The mediating role of social identity. Unpublished manuscript: University of Richmond. 
Mellers, B. A., Schwartz, A., Ho, K., \& Ritov, I. (1997). Decision affect theory: Emotional reactions to the outcomes of risky options. Psychological Science, 8, 423-429.

Mercurio, J. (2004, January 21). Dems gear up in New Hampshire. CNN. Retrieved February 10, 2004, from http://www.cnn.com/2004/ALLPOLITICS/01/21/elec04.prez.main/index.html Merriam-Webster, Online (2004). Retrieved May 23, 2004, from http://www.m-w.com/cgi-bin/dictionary?book=Dictionary\&va=underdog\&x=16\&y=8 Miller, D. T., \& Ratner, R. K. (1998). The disparity between the actual and assumed power of self-interest. Journal of Personality \& Social Psychology, 74, 53-62.

Nietzsche, F. (1967). On the genealogy of morals (W. Kaufmann \& R. J. Hollingdale, Trans.). New York: Random House. (Original work published 1887)

Pratto, F., Sidanius, J., Stallworth, L. M., \& Malle, B. F. (1994). Social dominance orientation: A personality variable predicting social and political attitudes. Journal of Personality and Social Psychology, 67, 741-763.

Schweitzer, K., Zillmann, D., Weaver, J. B., \& Luttrell, E. S. (1992). Perception of threatening events in the emotional aftermath of a televised college football game. Journal of Broadcasting \& Electronic Media, 36, 75-82.

Shepperd, J. A., \& McNulty, J. K. (2002). The affective consequences of expected and unexpected outcomes. Psychological Science, 13, 85-88.

Sidanius, J, \& Pratto, F. (1999). Social dominance: An intergroup theory of social hierarchy and oppression. New York: Cambridge University Press. 
Skitka, L. J., \& Tetlock, P.E. (1992). Allocating scares resources: A contingency model of distributive justice. Journal of Experimental Social Psychology, 28, 491-522.

Sloan, L. R. (1989). The motives of sports fans. In J. H. Goldstein (Ed.), Sports, games, and play: Social and psychological viewpoints (2nd ed., pp. 175-240). Hillsdale, NJ: Lawrence Erlbaum.

Smith, R. H., Turner, T. J., Garonzik, R., Leach, C. W., Druskat, V. U., \& Weston, C. M. (1996). Envy and schadenfreude. Personality and Social Psychology Bulletin, 22, 158-168.

Stone, J., Zachary, W. P., \& Darley, J. M. (1997). “White Men Can’t Jump”: Evidence for the Perceptual Confirmation of Stereotypes Following a Basketball Game. Basic and Applied Social Psychology, 19 (3), 291-306.

Stotland, E. (1969). The psychology of hope. San Francisco: Jossey-Bass.

Tajfel, H. (Ed.) (1978). Differentiation between social groups: Studies in the social psychology of intergroup relations. New York: Academic Press.

Tajfel, H., \& Turner, J. C. (1986). The social identity theory of intergroup behavior. In S. Worchel \& W. Austin (Eds.), Psychology of intergroup relations (2nd ed., pp. 7-24). Chicago, IL: Nelson-Hall.

Tesser, A. (1991). Emotion in social comparison and reflection processes. In J. Suls \& T. A. Wills (Eds.), Social comparison: Contemporary theory and research (pp. 115-145). Hillsdale, New Jersey: Laurence Erlbaum.

Thompson, L. (1995). “They saw a negotiation”: Partisanship and involvement. Journal of Personality and Social Psychology, 68, 839-853. 
Wann, D. L., \& Branscombe, N. R. (1990). Die-hard and fair-weather fans: Effects of identification on BIRGing and CORFing tendencies. Journal of Sport and Social Issues, 14, 103-117.

Wann, D. L., Keenan, B. L., Burnett, S., Martin, J., Page, L., Smith, L., \& Lantz, C. D. (2002). The Impact of Sport Team Identification and Attributions of Ability and Effort on Spectators’ Impressions of Athletic Performance. North American Journal of Psychology, 4 (3), 347-354.

Wann, D. L., Tucker, K. B., \& Schrader, M. P. (1996). An exploratory examination of the factors influencing the origination, continuation, and cessation of identification with sports teams. Perceptual and Motor Skills, 82, 995-1001.

Wills, T. A. (1991). Similarity and self-esteem in downward comparison. In J. Suls \& T. A. Wills (Eds.), Social comparison: Contemporary theory and research (pp. 51-78). Hillsdale, New Jersey: Laurence Erlbaum.

Zajonc, R. B. (1980). Feeling and thinking: Preferences need no inferences. American Psychologist, 35, 151-175. 
Appendices 
Appendix A: Study 1 Materials

1. General instructions for vignettes

2. Sports Core Scenarios

I. Unequal competition, no resources mentioned 68

II. Unequal competition plus resources matching status 69

III. Unequal competition plus resources not matching status 70

$\begin{array}{ll}\text { IV. Only resources mentioned } & 71\end{array}$

3. Sports Domain Vignettes

I. Unequal competition, no resources mentioned 72

II. Unequal competition plus resources matching status 73

III. Unequal competition plus resources not matching status 74

IV. Only resources mentioned $\quad 75$

V. Sports Questionnaire - Outcome Measure 76

4. Business Vignette and Questionnaire 77

$\begin{array}{ll}\text { 5. Political Vignette and Questionnaire } & 79\end{array}$

6. Social Dominance Questionnaire (for all six vignette conditions) 81 
Appendix A (Continued)

\section{A SOCIAL COMPETITION SCENARIO}

This questionnaire explores people's attitudes and beliefs about competitions. On the following pages, you will read a short news story. After reading the article, you will be asked a number of questions pertaining to the nature of the competition and your feelings about it. There are no right or wrong answers here; we are simply interested in people's opinions. Feel free to read the article as many times as you wish when answering the questions.

Please turn the page to begin the questionnaire. 


\section{Appendix A (Continued)}

Gender: $\quad M \quad F$

Imagine that two sports teams are about to play an important match. Based on past performance, the oddsmakers have assigned the following odds to the teams:

Team A: $\quad 70 \%$ of victory

Team B: $\quad 30 \%$ of victory

1. Not knowing anything else about the teams, which team do you think is probably going to win (circle one)?

Team A

Team B

2. How much would you like Team A to win the game?

$\begin{array}{lllllllll}1 & 2 & 3 & 4 & 5 & 6 & 7 & 8 & 9 \\ \begin{array}{l}\text { Not at } \\ \text { all }\end{array} & & & & \text { Mildly } & & & & \begin{array}{l}\text { Very } \\ \text { much }\end{array}\end{array}$

3. How much would you like Team B to win the game?

$\begin{array}{lllllllll}1 & 2 & 3 & 4 & 5 & 6 & 7 & 8 & 9 \\ \begin{array}{l}\text { Not at } \\ \text { all }\end{array} & & & & \text { Mildly } & & & \begin{array}{l}\text { Very } \\ \text { much }\end{array}\end{array}$

4. As a first impression, which team do you like better (circle one)?
Team A
Team B

5. Not knowing anything else about the teams, which team would you probably root for (circle one)?

Team A Team B

6. Which team, if any, is the "underdog"? Why? 


\section{Appendix A (Continued)}

Gender: $\quad M \quad F$

Imagine that two sports teams are about to play an important match. Based on past performance, the oddsmakers have assigned the following odds to the teams. In addition to knowing their chances for a victory, you also learn the following information about the teams' payrolls:

Team A: $70 \%$ of victory; Team payroll: $\$ 100$ million dollars Team B: $30 \%$ of victory; Team payroll: $\$ 35$ million dollars

1. Not knowing anything else about the teams, which team do you think is probably going to win (circle one)?

Team A

Team B

2. How much would you like Team A to win the game?

$\begin{array}{lllllllll}1 & 2 & 3 & 4 & 5 & 6 & 7 & 8 & \begin{array}{l}9 \\ \text { Very } \\ \text { much }\end{array} \\ \text { all } & & & & \text { Mildly } & & & & \end{array}$

3. How much would you like Team B to win the game?

$\begin{array}{lllllllll}1 & 2 & 3 & 4 & 5 & 6 & 7 & 8 & \begin{array}{l}9 \\ \text { Very } \\ \text { much }\end{array} \\ \begin{array}{l}\text { Not at } \\ \text { all }\end{array} & & & & \text { Mildly } & & & & \end{array}$

4. As a first impression, which team do you like better (circle one)?

Team A

Team B

5. Not knowing anything else about the teams, which team would you probably root for (circle one)?

Team A

Team B

6. Which team, if any, is the "underdog"? Why? 


\section{Appendix A (Continued)}

Gender: $\quad M \quad F$

Imagine that two sports teams are about to play an important match. Based on past performance, the oddsmakers have assigned the following odds to the teams. In addition to knowing their chances for a victory, you also learn the following information about the teams' payrolls:

Team A: $70 \%$ of victory; Team payroll: $\$ 35$ million dollars

Team B: $30 \%$ of victory; Team payroll: $\$ 100$ million dollars

1. Not knowing anything else about the teams, which team do you think is probably going to win (circle one)?

\section{Team A \\ Team B}

2. How much would you like Team A to win the game?

$\begin{array}{lllllllll}1 & 2 & 3 & 4 & 5 & 6 & 7 & 8 & \begin{array}{l}\text { Very } \\ \text { much } \\ \text { all }\end{array}\end{array}$

3. How much would you like Team B to win the game?

$\begin{array}{lllllllll}1 & 2 & 3 & 4 & 5 & 6 & 7 & 8 & 9 \\ \begin{array}{l}\text { Not at } \\ \text { all }\end{array} & & & & \text { Mildly } & & & \begin{array}{l}\text { Very } \\ \text { much }\end{array}\end{array}$

4. As a first impression, which team do you like better (circle one)?

Team A Team B

5. Not knowing anything else about the teams, which team would you probably root for (circle one)?

Team A

Team B

6. Which team, if any, is the "underdog"? Why? 


\section{Appendix A (Continued)}

Gender: $\quad M \quad F$

Imagine that two sports teams are about to play an important match. The only thing you know about the teams are their payrolls:

Team A: payroll: $\$ 35$ million dollars

Team B: payroll: $\$ 100$ million dollars

1. Not knowing anything else about the teams, which team do you think is probably going to win (circle one)?

\section{Team A $\quad$ Team B}

2. How much would you like Team A to win the game?

$\begin{array}{lllllllll}1 & 2 & 3 & 4 & 5 & 6 & 7 & 8 & \begin{array}{l}9 \\ \text { Very } \\ \text { much }\end{array} \\ \begin{array}{l}\text { Not at } \\ \text { all }\end{array} & & & & \text { Mildly } & & & & \end{array}$

3. How much would you like Team B to win the game?

$\begin{array}{lllllllll}1 & 2 & 3 & 4 & 5 & 6 & 7 & 8 & \begin{array}{l}9 \\ \text { Very } \\ \text { much }\end{array} \\ \begin{array}{l}\text { Not at } \\ \text { all }\end{array} & & & & \text { Mildly } & & & & \end{array}$

4. As a first impression, which team do you like better (circle one)?
Team A
Team B

5. Not knowing anything else about the teams, which team would you probably root for (circle one)?

Team A

Team B

6. Which team, if any, is the "underdog"? Why? 
Appendix A (Continued)

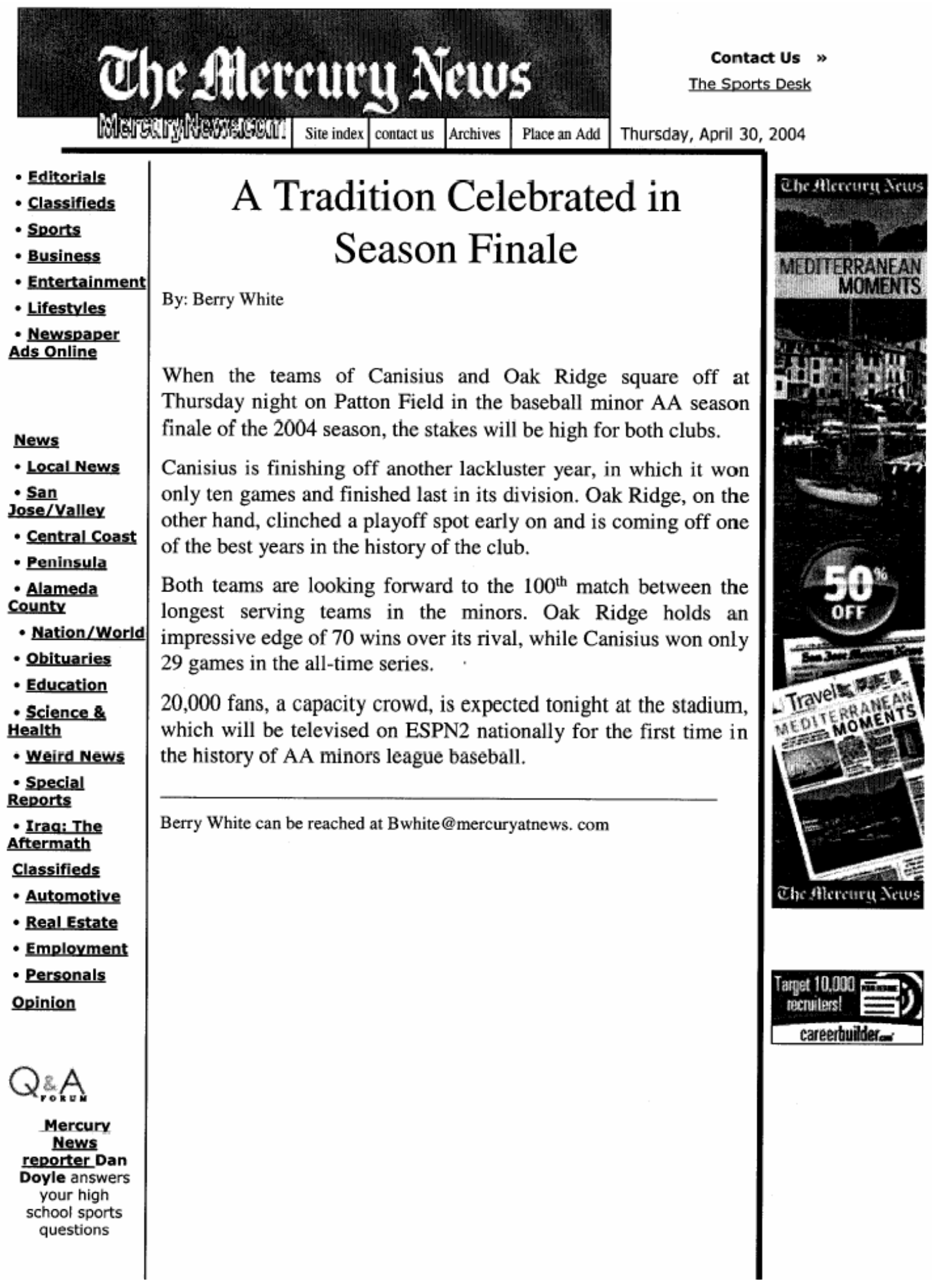




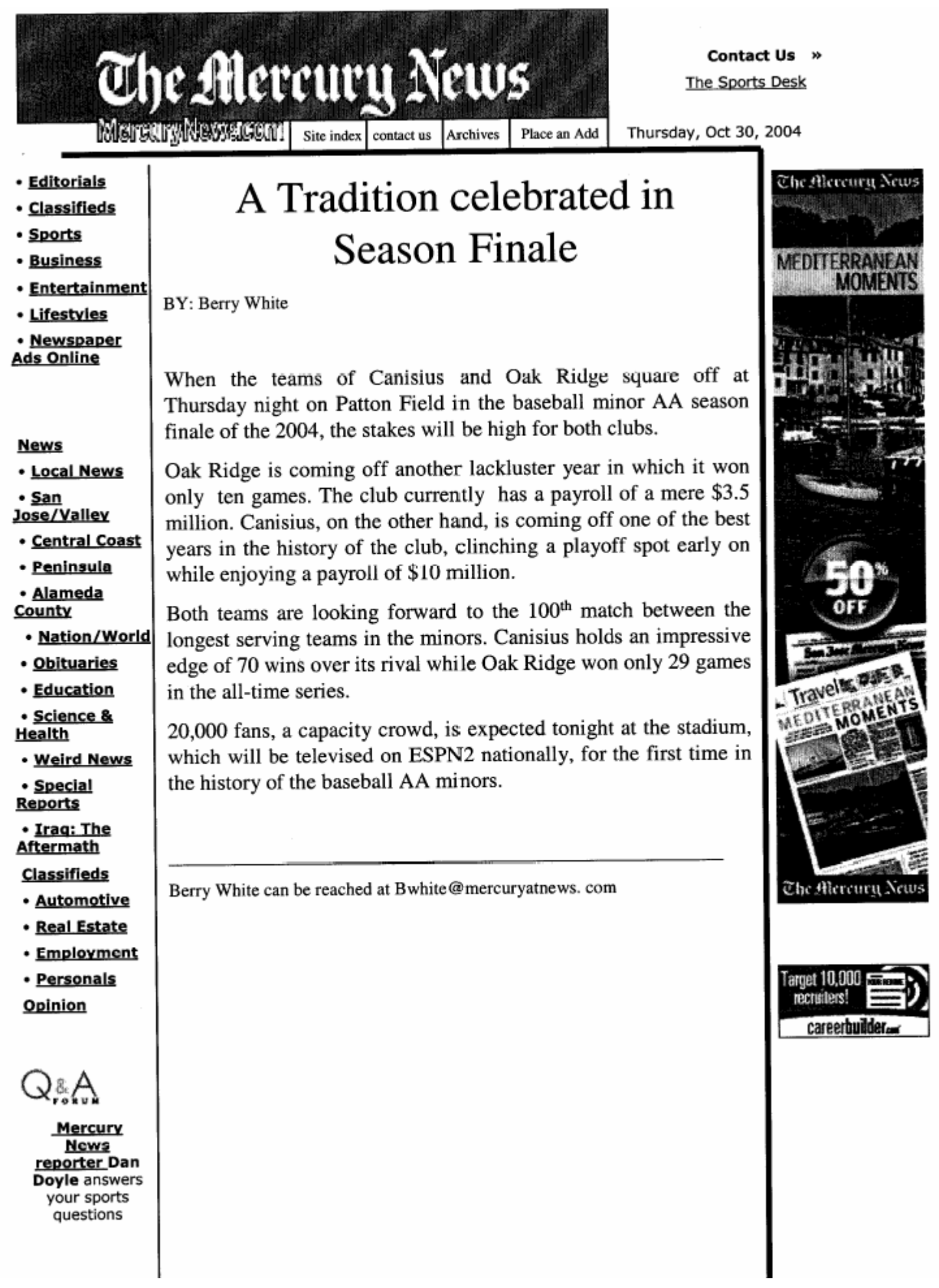




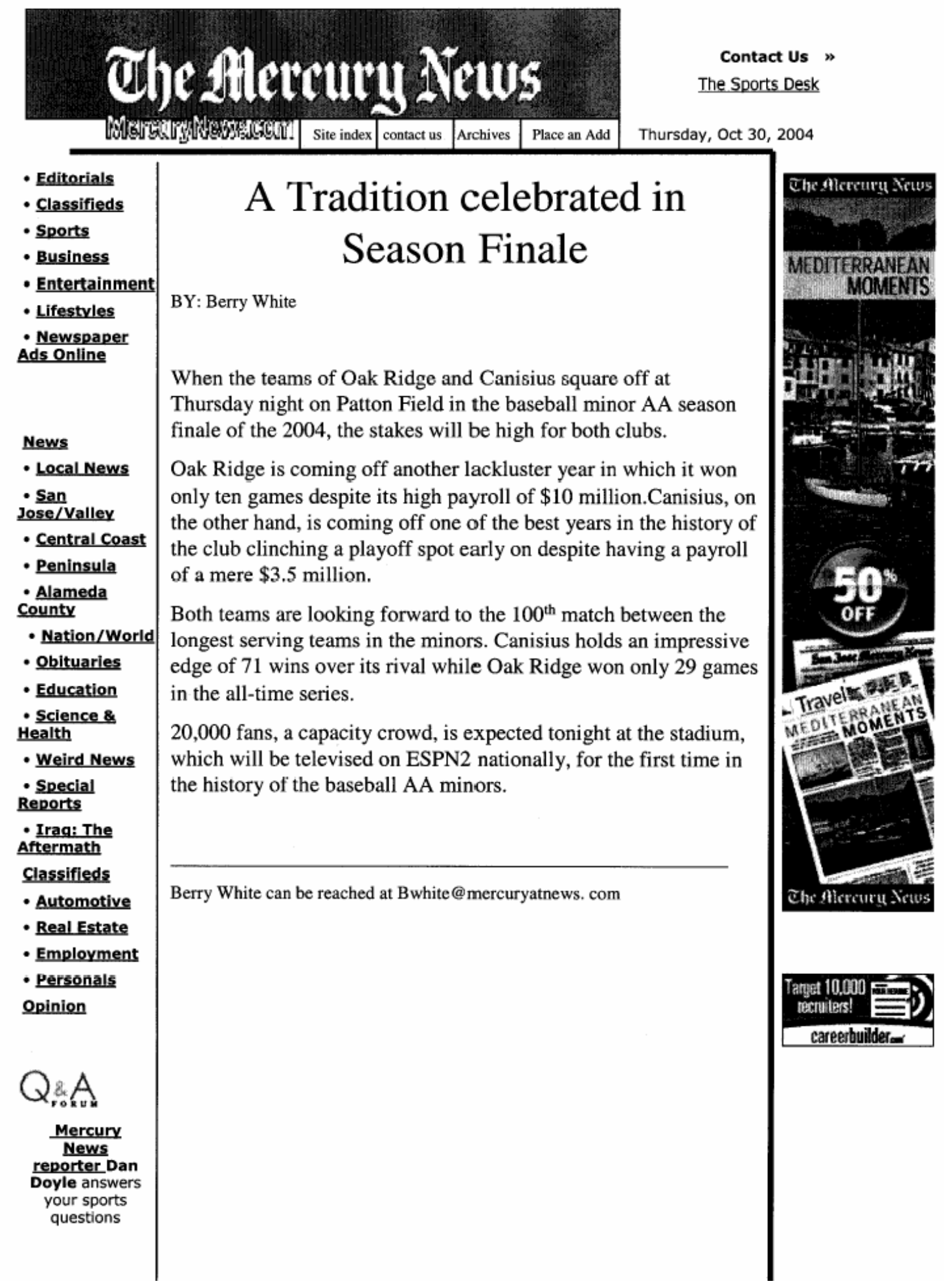




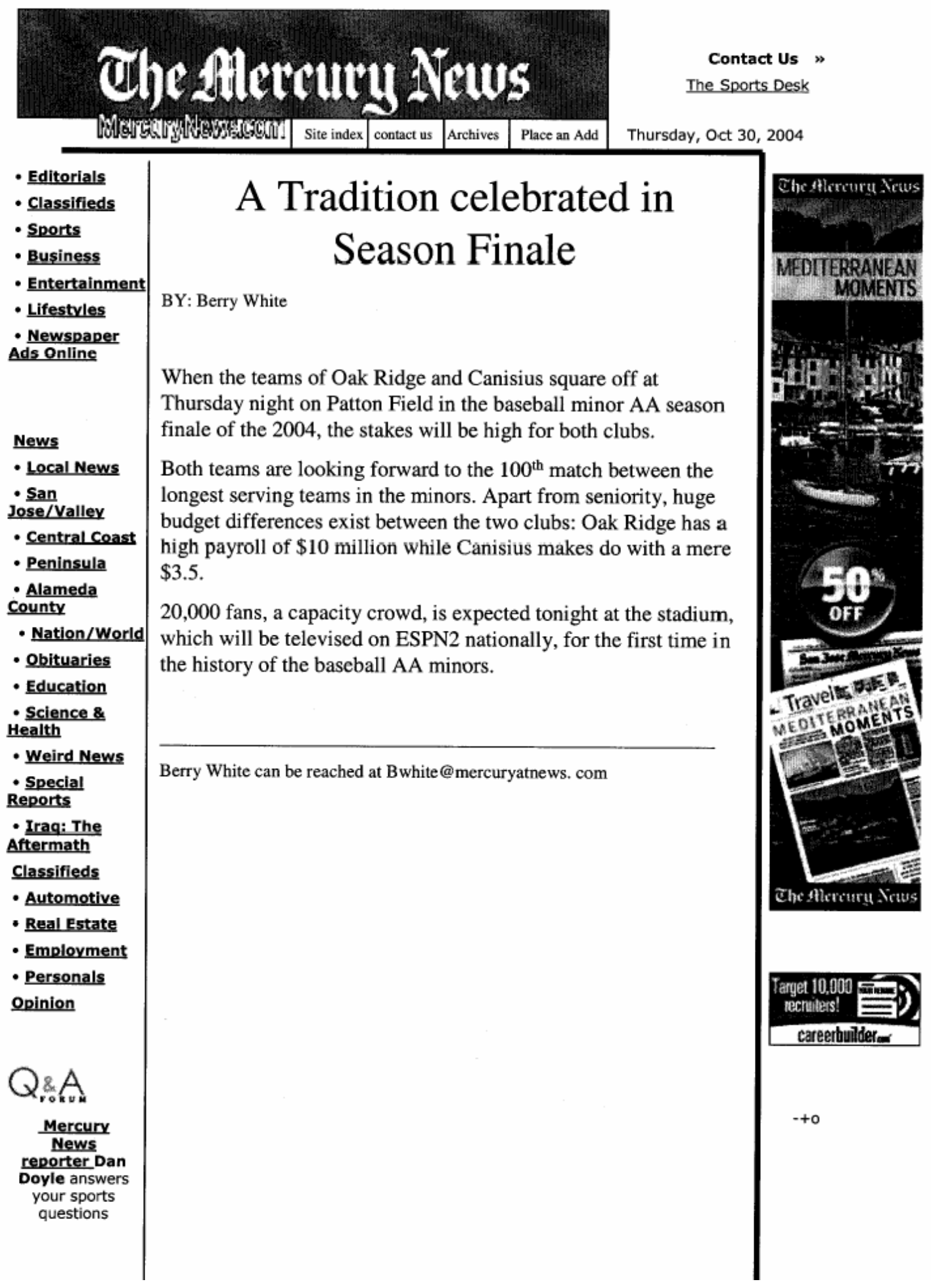




\section{Appendix A (Continued)}

Gender: $M \quad F$

1. Not knowing anything else about the teams, which team do you think is probably going to win (circle one)?
Canisius
Oak Ridge

2. How much would you like Canisius to win the game?

$\begin{array}{lllllllll}1 & 2 & 3 & 4 & 5 & 6 & 7 & 8 & \begin{array}{l}9 \\ \text { Very } \\ \text { much } \\ \text { all at }\end{array}\end{array}$

3. How much would you like Oak Ridge to win the game?

$\begin{array}{lllllllll}1 & 2 & 3 & 4 & 5 & 6 & 7 & 8 & \begin{array}{l}9 \\ \text { Very } \\ \text { much }\end{array} \\ \begin{array}{l}\text { Not at } \\ \text { all }\end{array} & & & & \text { Mildly } & & & & \end{array}$

4. As a first impression, which team do you like better (circle one)?
Canisius
Oak Ridge

5. Not knowing anything else about the teams, which team would you probably root for (circle one)?

Canisius Oak Ridge

6. Which team, if any, is the "underdog"? Why? 
Appendix A (Continued)

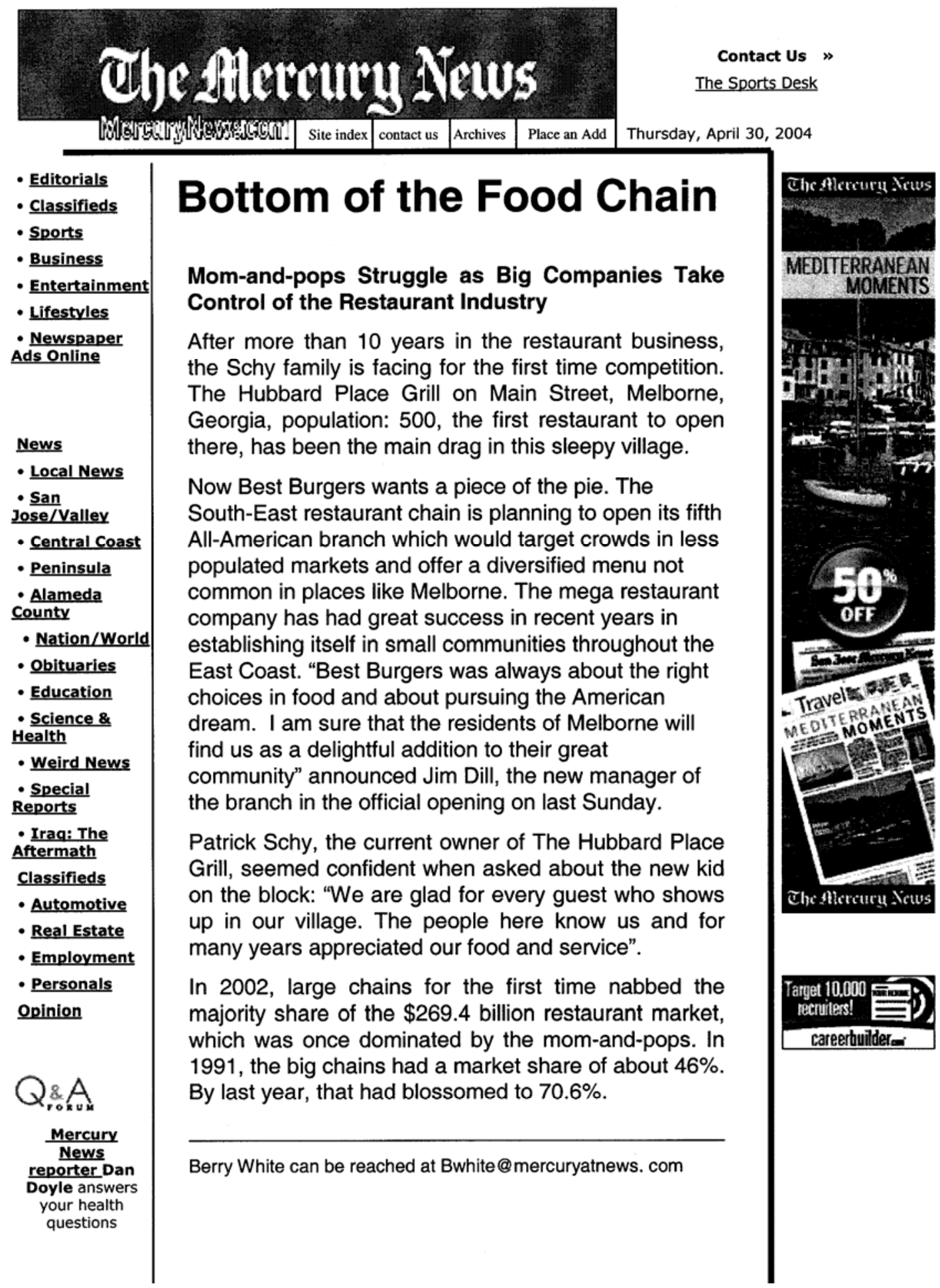


Gender: $\quad M \quad F$

1. Not knowing anything else about the restaurants, which one do you think is probably going to do better financially in the future (circle one)?

\section{Hubbard Place Grill Best Burgers}

2. How much would you like to see Hubbard Place Grill succeed in the future?

$\begin{array}{lllllllll}1 & 2 & 3 & 4 & 5 & 6 & 7 & 8 & \begin{array}{l}9 \\ \text { Very } \\ \text { much }\end{array} \\ \begin{array}{l}\text { Not at } \\ \text { all }\end{array} & & & & \text { Mildly } & & & & \end{array}$

3. How much would you like to see Best Burgers succeed in the future?

$\begin{array}{lllllllll}1 & 2 & 3 & 4 & 5 & 6 & 7 & 8 & \begin{array}{l}9 \\ \text { Very } \\ \text { much }\end{array} \\ \text { all } & & & & \text { Mildly } & & & & \end{array}$

4. As a first impression, which restaurant do you like better (circle one)?

$$
\text { Hubbard Place Grill Best Burgers }
$$

5. Not knowing anything else about the restaurants, which one would you probably dine in (circle one)?

$$
\text { Hubbard Place Grill Best Burgers }
$$

6. Which restaurant, if any, is the "underdog"? Why? 


\section{Appendix A (Continued)}

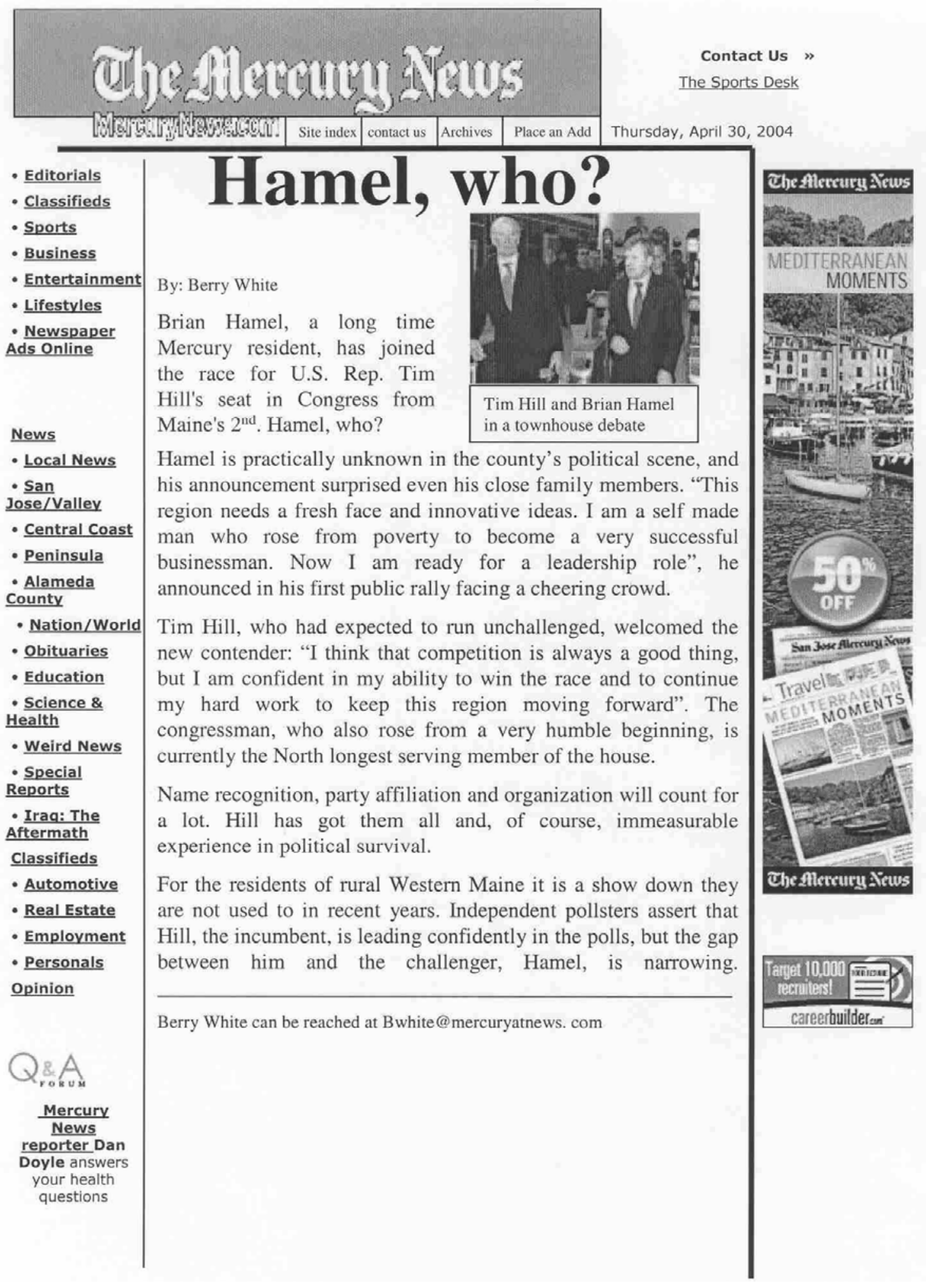




\section{Appendix A (Continued)}

Gender: $\quad M \quad F$

1. Not knowing anything else about the candidates, which one do you think is probably going to win the elections (circle one)?

\section{Brain Hamel Tim Hill}

2. How much would you like Hamel to win the election?

$\begin{array}{lllllllll}1 & 2 & 3 & 4 & 5 & 6 & 7 & 8 & \begin{array}{l}9 \\ \text { Very } \\ \text { much }\end{array} \\ \text { all at } & & & & \text { Mildly } & & & & \end{array}$

3. How much would you like Tim Hill to win the election?

$\begin{array}{lllllllll}1 & 2 & 3 & 4 & 5 & 6 & 7 & 8 & \begin{array}{l}9 \\ \text { Very } \\ \text { much }\end{array} \\ \begin{array}{l}\text { Not at } \\ \text { all }\end{array} & & & & \text { Mildly } & & & & \end{array}$

4. As a first impression, which candidate do you like better (circle one)?

Brain Hamel

Tim Hill

5. Not knowing anything else about the candidates, which one would you probably vote for (circle one)?

Brian Hamel Tim Hill

6. Which candidate, if any, is the "underdog"? Why? 


\section{Appendix A (Continued)}

Below are a series of statements with which you may either agree or disagree. For each statement, please indicate the degree of your agreement/disagreement by writing the appropriate number from 1 to 7 in the blanks beside the questions. Remember that your first responses are usually the most accurate.

\begin{tabular}{|c|c|c|c|c|c|c|}
\hline Strongly & Slightly & & Neither Agree & Slightly & & Strongly \\
\hline Disagree & Disagree & Disagree & nor Disagree & Agree & Agree & Agree \\
\hline 1 & 2 & 3 & 4 & 5 & 6 & 7 \\
\hline
\end{tabular}

1. Some groups of people are simply inferior to other groups.

2. In getting what you want, it is sometimes necessary to use force against other groups.

3. It's OK if some groups have more of a chance in life than others.

4. To get ahead in life, it is sometimes necessary to step on other groups.

5. If certain groups stayed in their place, we would have fewer problems.

6. It's probably a good thing that certain groups are at the top and other groups are at the bottom.

7. Inferior groups should stay in their place.

_ 8. Sometimes other groups must be kept in their place.

9. It would be good if groups could be equal.

10. Group equality should be our ideal.

11. All groups should be given an equal chance in life.

12. We should do what we can to equalize conditions for different groups.

13. We would have fewer problems if we treated people more equally.

14. We should strive to make incomes as equal as possible.

15. No one group should dominate in society. 
Appendix B: Study 2 Materials

1. General instructions for vignettes 83

2. $\quad$ Sports Domain Vignettes: Framing

I. Unequal competition no resources mentioned 84

II. Unequal competition plus resources matching status 85

III. Win Framing Questionnaire 86

IV. Lose Framing Questionnaire $\quad 87$ 
Appendix B (Continued)

\section{A SOCIAL COMPETITION SCENARIO}

This questionnaire explores people's attitudes and beliefs about competitions. On the following pages, you will read a short news story. After reading the article, you will be asked a number of questions pertaining to the nature of the competition and your feelings about it. There are no right or wrong answers here; we are simply interested in people's opinions. Feel free to read the article as many times as you wish when answering the questions.

Please turn the page to begin the questionnaire. 
Appendix B (Continued)

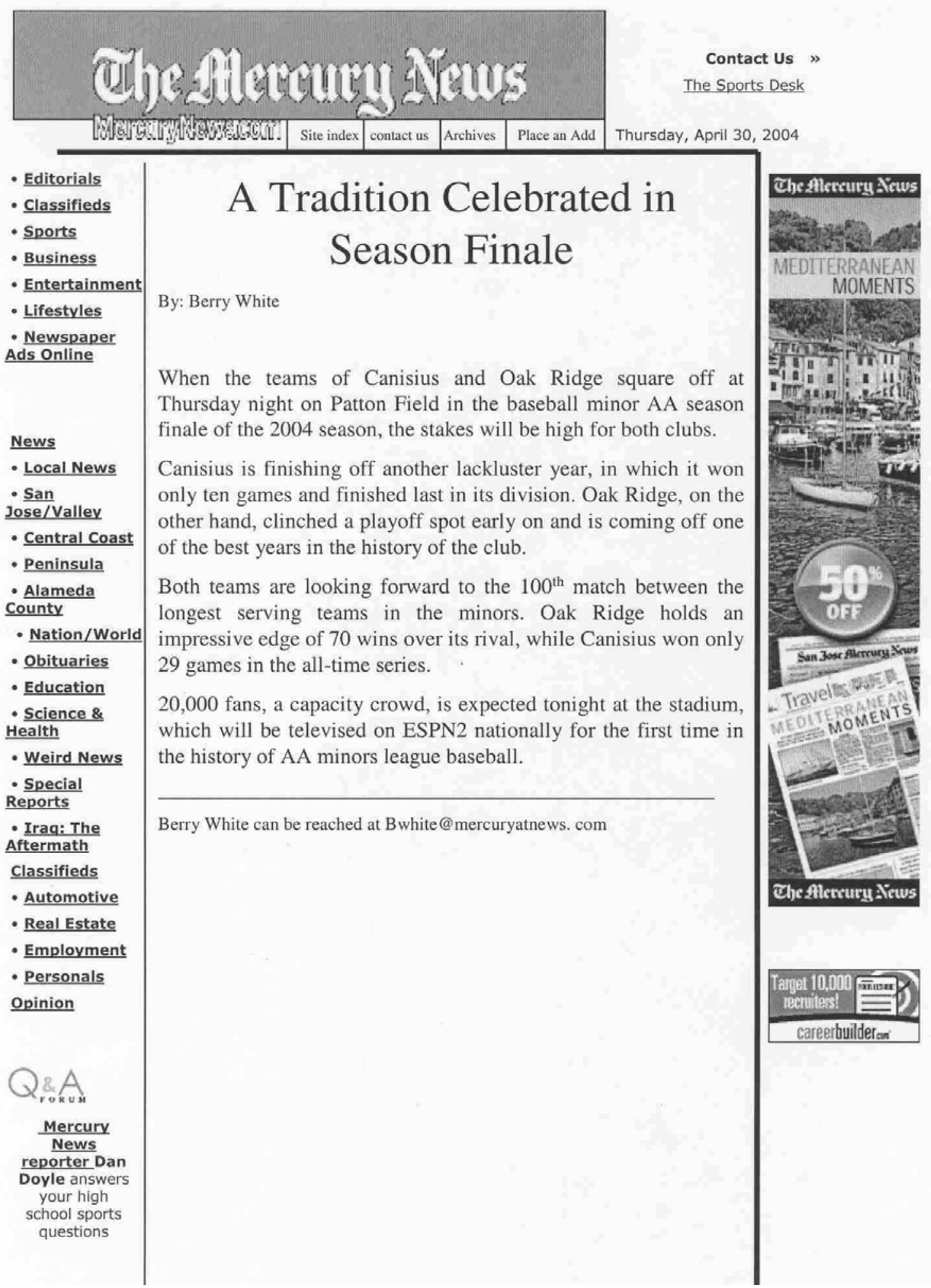




\section{Appendix B (Continued)}

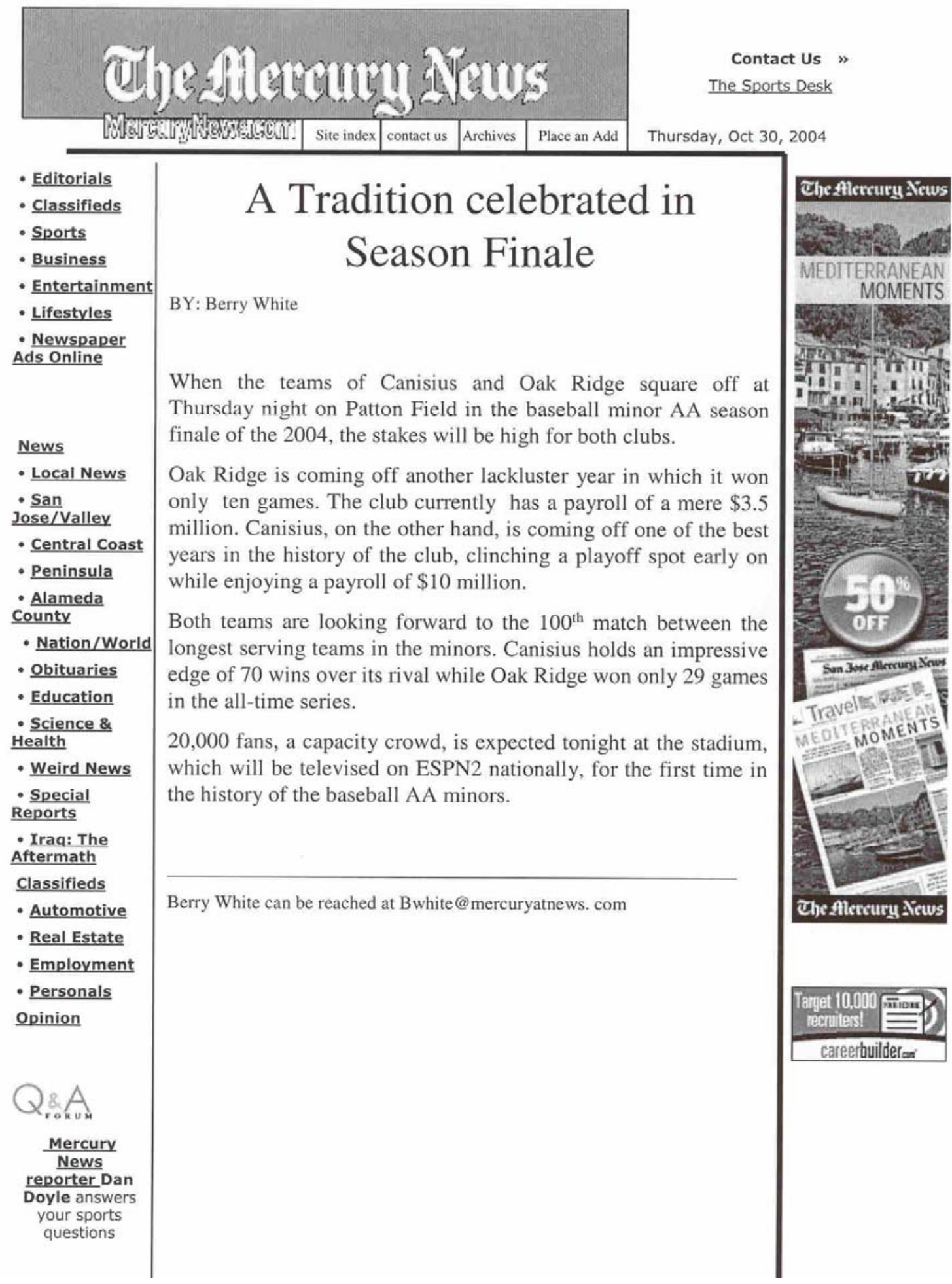


Gender: $\quad M \quad F$

Based on the article you just read, we are interested in capturing your thoughts about the two teams and the game they are about to play. Feel free to read the scenario as many times as you wish, when answering the following questions:

1. How much would you like Oak Ridge to win the game?

$\begin{array}{lllllllll}1 & 2 & 3 & 4 & 5 & 6 & 7 & 8 & 9 \\ \begin{array}{l}\text { Not at } \\ \text { all }\end{array} & & & & \text { Mildly } & & & & \begin{array}{l}\text { Very } \\ \text { much }\end{array}\end{array}$

2. How much would you like Clinton to win the game?

$\begin{array}{lllllllll}1 & 2 & 3 & 4 & 5 & 6 & 7 & 8 & 9 \\ \begin{array}{l}\text { Not at } \\ \text { all }\end{array} & & & & \text { Mildly } & & & & \begin{array}{l}\text { Very } \\ \text { much }\end{array}\end{array}$


Gender: $\quad M$

$$
\text { F }
$$

Based on the article you just read, we are interested in capturing your thoughts about the two teams and the game they are about to play. Feel free to read the scenario as many times as you wish, when answering the following questions:

1. How much would you like Oak Ridge to lose the game?

$\begin{array}{lllllllll}1 & 2 & 3 & 4 & 5 & 6 & 7 & 8 & \begin{array}{l}9 \\ \text { Very } \\ \text { much }\end{array} \\ \text { all at } & & & & \text { Mildly } & & & & \end{array}$

2. How much would you like Clinton to lose the game?

$\begin{array}{lllllllll}1 & 2 & 3 & 4 & 5 & 6 & 7 & 8 & 9 \\ \begin{array}{l}\text { Not at } \\ \text { all }\end{array} & & & & \text { Mildly } & & & & \begin{array}{l}\text { Very } \\ \text { much }\end{array}\end{array}$


Appendix C: Study 3 Materials

1. General instructions for vignettes 89

2. Spoiler Sports Vignettes

I. No spoiler, no resources mentioned 90

II. Spoiler, no resources mentioned 91

$\begin{array}{ll}\text { III. Spoiler plus resources matching status } & 92\end{array}$

IV. No spoiler plus resources matching status 93

3. Sports Questionnaire - Outcome Measure 94 
Appendix C (Continued)

\section{A SOCIAL COMPETITION SCENARIO}

This questionnaire explores people's attitudes and beliefs about competitions. On the following pages, you will read a short news story. After reading the article, you will be asked a number of questions pertaining to the nature of the competition and your feelings

about it. There are no right or wrong answers here; we are simply interested in people’s opinions. Feel free to read the article as many times as you wish when answering the questions.

Please turn the page to begin the questionnaire. 
Appendix C (Continued)

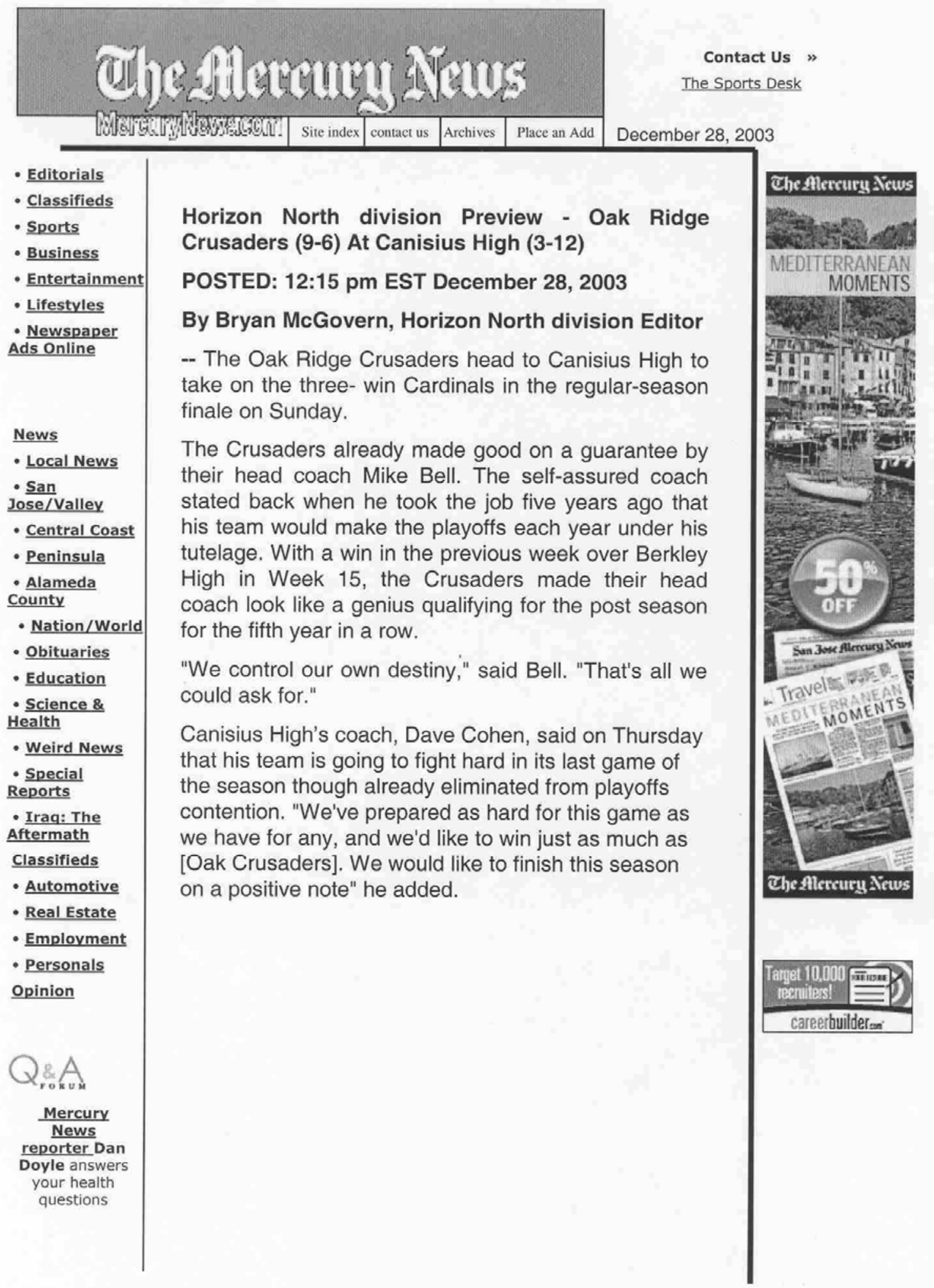


Appendix C (Continued)

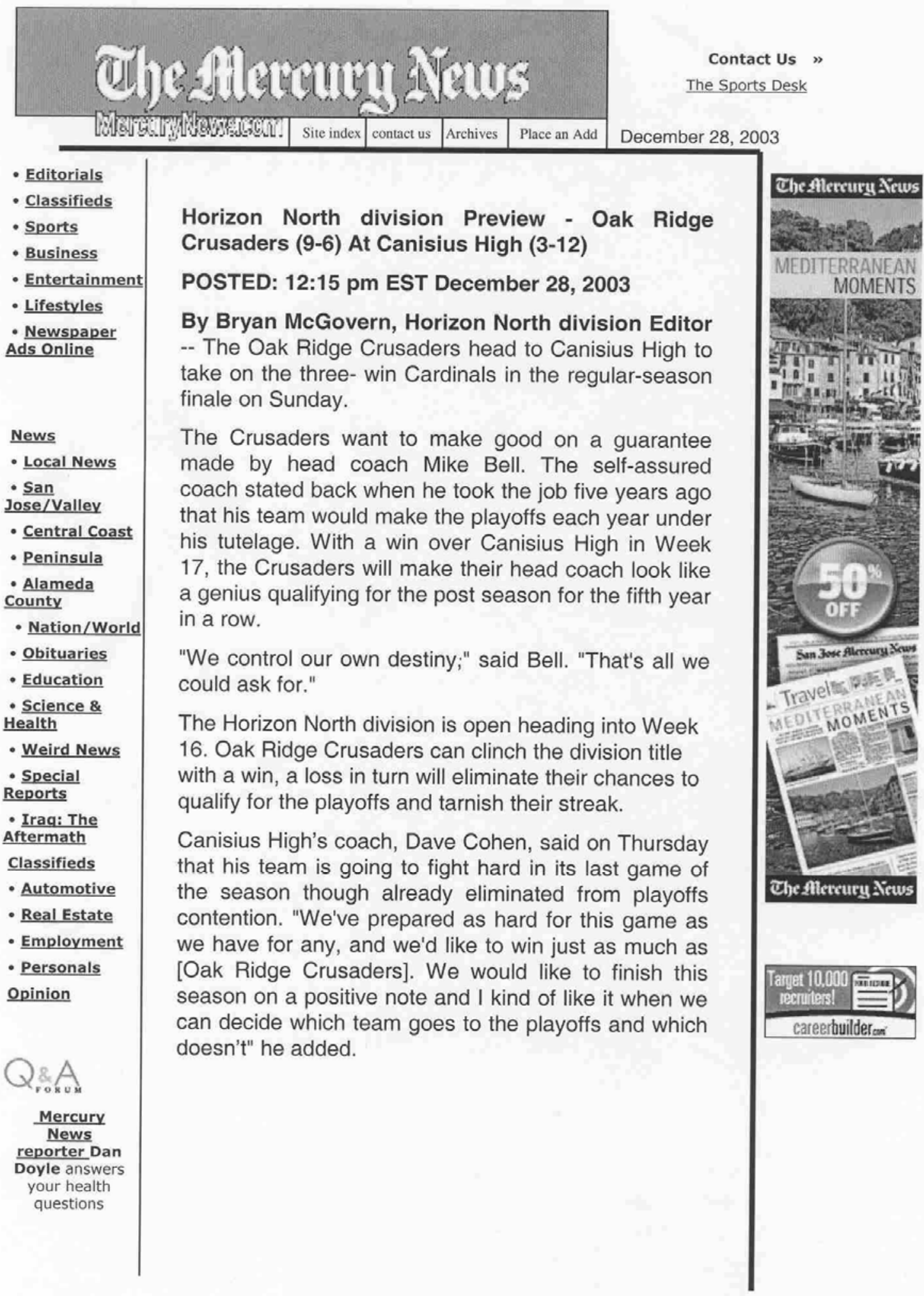


Appendix C (Continued)

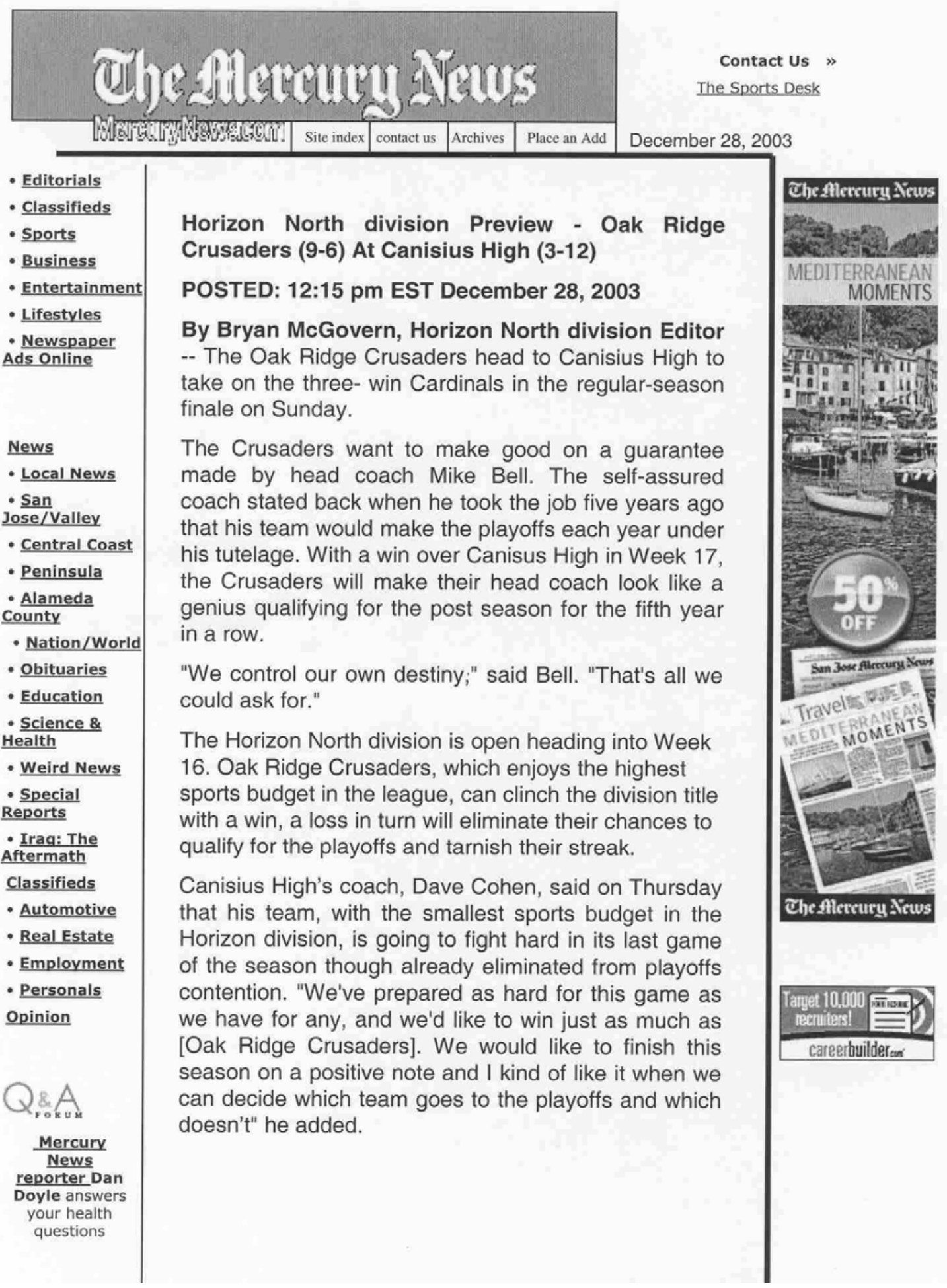


Appendix C (Continued)

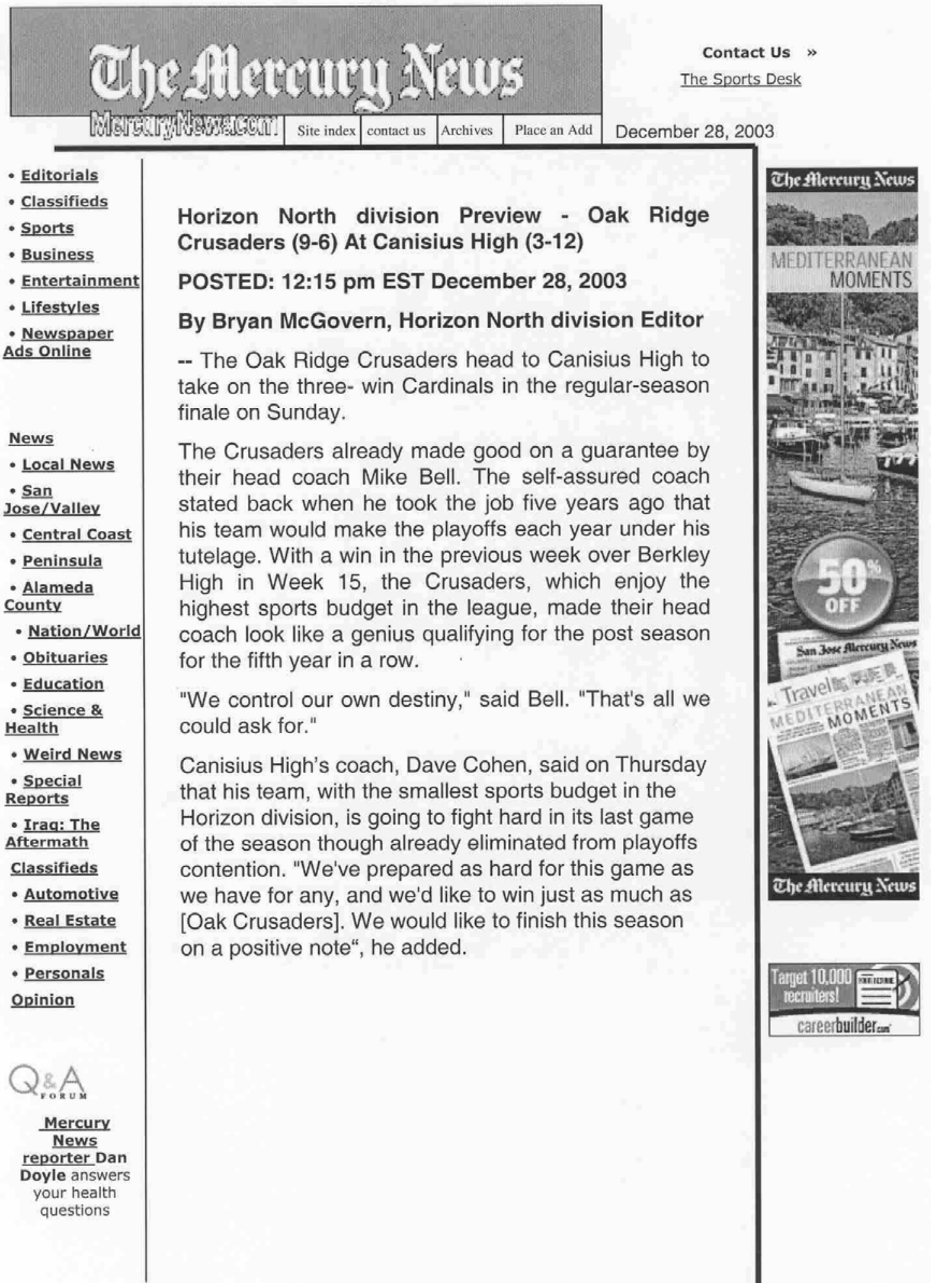




\section{Appendix C (Continued)}

Gender: $\quad M \quad F$

1. Not knowing anything else about the teams, which team do you think is probably going to win (circle one)?
Canisius
Oak Ridge

2. How much would you like Canisius to win the game?

$\begin{array}{lllllllll}1 & 2 & 3 & 4 & 5 & 6 & 7 & 8 & \begin{array}{l}9 \\ \text { Very } \\ \text { much }\end{array} \\ \begin{array}{l}\text { Not at } \\ \text { all }\end{array} & & & & \text { Mildly } & & & & \end{array}$

3. How much would you like Oak Ridge to win the game?

$\begin{array}{lllllllll}1 & 2 & 3 & 4 & 5 & 6 & 7 & 8 & \begin{array}{l}\text { Very } \\ \text { much }\end{array} \\ \begin{array}{l}\text { Not at } \\ \text { all }\end{array} & & & & \text { Mildly } & & & & \end{array}$

4. As a first impression, which team do you like better (circle one)?
Canisius
Oak Ridge

5. Not knowing anything else about the teams, which team would you probably root for (circle one)?
Canisius
Oak Ridge

6. Which team, if any, is the "underdog"? Why? 
Appendix D: Study 4 Materials

1. Memory Vignettes

I. Unequal competition, no resources mentioned 96

II. Unequal competition plus resources matching status 97

III. Pre-video watching underdog questionnaire 98

IV. Recall/Recognition Questionnaire 99

V. Attributions Questionnaire 102 


\section{Appendix D (Continued)}

Dear participant,

You are about to watch a 15 minute basketball clip between two European teams:

Maccabi Tel-Aviv, an Israeli team, and CSKA Moscow, a Russian team. This is one of the fiercest sports rivalries outside of the USA boundaries and is often compared to the famed Yankees-Red Sox long rivalry particularly because it has also been a one-sided affair.

CSKA Moscow has beaten Maccabi Tel-Aviv CSKA Moscow in all of their previous playoff games running back 15 years but this is the first time they meet in the semi-finals of the prestigious Euroleague cap and the winner will go on to play in the finals and most assuredly win the $\$ 1$ million prize. The game is held in Tel-Aviv and hence the locals will be strongly pushed by their rabid fans. The line on this game is $90 \%$ a CSKA Moscow win.

But this rivalry goes even beyond the court as the two teams feel strongly towards each other as can be seen from the coaches remarks just prior to tonight's game. Pini Gershon, the Maccabi Tel-Aviv coach, said: "It is about time we beat them after so much losing. I can see the light in the end of the tunnel". Dusan Ivkovich, the CSKA Moscow coach was quick to counter: "there is no way we are going to lose to them. It is far too important for us!".

We would like to test your 'basketball' analysis and predictions skills to guess the final score based on the data provided here and a short clip of the final stages of the game itself. Are there any questions before we begin?

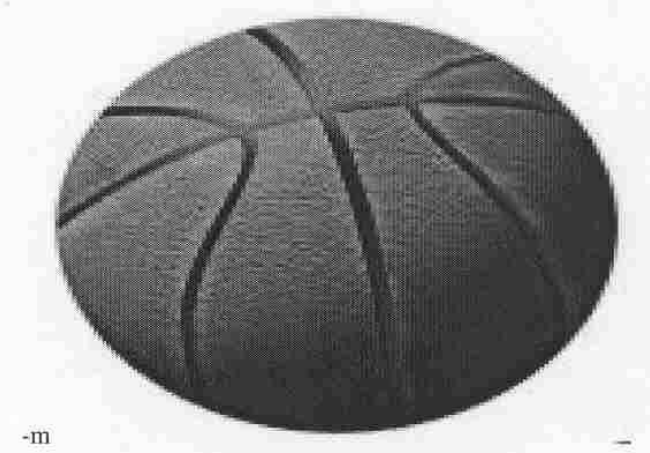




\section{Appendix D (Continued)}

Dear participant,

You are about to watch a 15 minute basketball clip between two European teams: Maccabi Tel-Aviv, an Israeli team, and CSKA Moscow, a Russian team. This is one of the fiercest sports rivalries outside of the USA boundaries and is often compared to the famed Yankees-Red Sox long rivalry particularly because it has also been a one-sided affair.

Maccabi Tel-Aviv has beaten CSKA Moscow in all of their previous playoff games running back 15 years but this is the first time they meet in the semi-finals of the prestigious Euroleague cap and the winner will go on to play in the finals and most assuredly win the $\$ 1$ million prize. The financial benefit associated with winning the championship is highly important for CSKA Moscow as its whole annual payrollis a mere \$1 million whereas the Maccabi Tel-Aviv is the richest in Europe with a \$20 million yearlypayroll. The game is held in Tel-Aviv and hence the locals will be strongly pushed by their rabid fans. The line on this game is $90 \%$ a Maccabi Tel-Aviv win.

But this rivalry goes even beyond the court as the two teams feel strongly towards each other as can be seen from the coaches remarks just prior to tonight's game. Dusan Ivkovich, the CSKA Moscow coach, said: "It is about time we beat them after so much losing. I can see the light in the end of the tunnel". Pini Gershon, the Maccabi Tel-Aviv coach, was quick to counter: "there is no way we are going to lose to them. It is far too important for us!".

We would like to test your 'basketball' analysis and predictions skills to guess the final score based on the data provided here and a short clip of the final stages of the game itself. Are there any questions before we begin?

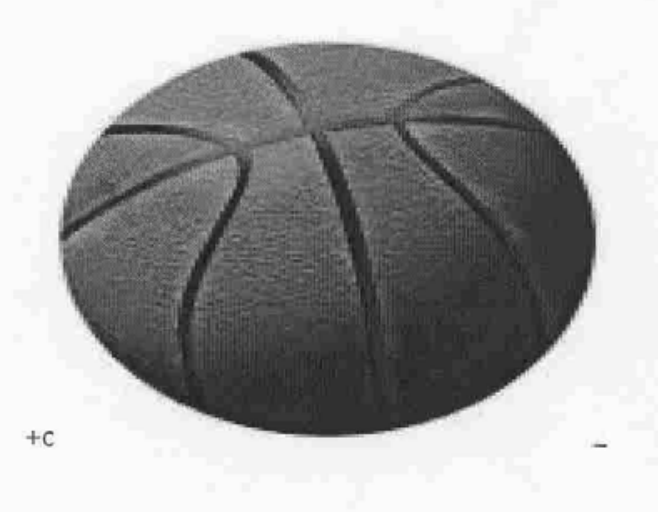


Appendix D (Continued)

Please Specify Your Gender: $\quad M \quad F$

1. Not knowing anything else about the teams, which team do you think is probably going to win (circle one)?
CSKA Moscow
Maccabi Tel-Aviv

2. How much would you like CSKA Moscow to win the game?

$\begin{array}{lllllllll}1 & 2 & 3 & 4 & 5 & 6 & 7 & 8 & \begin{array}{l}9 \\ \text { Very } \\ \text { much }\end{array} \\ \begin{array}{l}\text { Not at } \\ \text { all }\end{array} & & & & \text { Mildly } & & & & \end{array}$

3. How much would you like Maccabi Tel-Aviv to win the game?

$\begin{array}{lllllllll}1 & 2 & 3 & 4 & 5 & 6 & 7 & 8 & \begin{array}{l}9 \\ \text { Very } \\ \text { much }\end{array} \\ \begin{array}{l}\text { Not at } \\ \text { all }\end{array} & & & & \text { Mildly } & & & & \end{array}$

4. As a first impression, which team do you like better (circle one)?

$$
\text { CSKA Moscow Maccabi Tel-Aviv }
$$

5. Not knowing anything else about the teams, which team would you probably root for (circle one)?
CSKA Moscow
Maccabi Tel-Aviv

6. Which team, if any, is the "underdog"? Why? 


\section{Appendix D (Continued)}

Dear participants,

We would like to ask you few recall questions about the game you have just watched.

Don't worry about misspelling, as some of the names are not common. We are only interested in your overall memory level.

1. Your Gender (circle): $\quad$ M $\quad F$

2. Name the teams/ cities / countries:

3. Name the colors of the teams:

4. Name any players that you remember (do not be concerned with the 'right' spelling):

5. Name any jersey numbers: 


\section{Appendix D (Continued)}

\section{-DO NOT TURN BACK-}

We would like to test your memory on various details of the game you just watched:

1. Please circle the one player in each pair that has taken part in the game (if you don't exactly recall go with your gut feeling!).

1. Maceo Baston or Thornton Marvis

2. Stefanov Vrbica or Sergey Monya

3. Theodoros Papaloukas or Kakiouzis Mikalis

4. Dragan Tarlac or Smodis Matjaz

5. Anderson David or Anthony Parker

6. Mancinelli Stefano or Nikola Vujcic

7. Zukauskas Mindaugas or Gur Shelef

8. John Holden or John Best

9. Tal Burstein or Ben-Schmiol Avi

10. Victor Khrypa or Mithat Demirel

11. Gilbert Clarence or Marcus Brown

12. Sarunas Jasikevicius or Garcia Asier

13. Deon Thomas or Kyle Hill

14. Larry Lewis or David Bluthental

15. Mirsad Turckan or Mirko Kovac

16. Lev Green or Aleksey Savarasenko 
Appendix D (Continued)

\section{-DO NOT TURN BACK-}

2. Which numbers did the following players had on the jersey (circle)?

1 Sergey Monya $12 \quad 4$

2 Theodoros Papaloukas $\quad 4 \quad 11$

3 Anthony Parker $\quad 15 \quad 8$

4 Nikola Vujcic $\quad 21 \quad 7$

5 Gur Shelef $\quad 9 \quad 16$

6 John Holden $\quad 5 \quad 10$

7 Tal Burstein $\quad 10 \quad 21$

8 Victor Khrypa $13 \quad 6$

9 Marcus Brown $\quad 10 \quad 5$

10 Sarunas Jasikevicius $\quad 13 \quad 21$

11 Deon Thomas $\quad 6 \quad 15$

12 Aleksey Savarasenko $\quad 14 \quad 9$

13 David Bluthental 933

14 Mirsad Turckan $\quad 10 \quad 16$

\section{What was the final score (circle)?}

1. Moscow 54 to 62 Tel Aviv

2. Moscow 55 to 61 Tel Aviv

3. Moscow 56 to 61 Tel Aviv

4. Moscow 55 to 62 Tel Aviv 


\section{Appendix D (Continued)}

For this next section, we are interested on why you believe each team performed as it did.

Please answer the following questions about each team.

First, consider the Maccabi Tel Aviv team (in the yellow jerseys).Think about the performance of this team as a whole when you answer the following questions:

\section{How much hustle did Maccabi Tel Aviv show?}

$\begin{array}{lllll}1 & 2 & 3 & 4 & 5 \\ \text { None at all } & \text { A little } & \text { Some } & \text { Quite a bit } & \text { A great deal }\end{array}$

\section{How much natural ability did this team have?}

$\begin{array}{lllll}1 & 2 & 3 & 4 & 5 \\ \text { None at all } & \text { A little } & \text { Some } & \text { Quite a bit } & \text { A great deal }\end{array}$

\section{How much effort did this team put forth?}

$\begin{array}{lllll}1 & 2 & 3 & 4 & 5 \\ \text { None at all } & \text { A little } & \text { Some } & \text { Quite a bit } & \text { A great deal }\end{array}$

\section{How much heart did this team show?}

$\begin{array}{lllll}1 & 2 & 3 & 4 & 5 \\ \text { None at all } & \text { A little } & \text { Some } & \text { Quite a bit } & \text { A great deal }\end{array}$

\section{How much intelligence did this team show?}

$\begin{array}{lllll}1 & 2 & 3 & 4 & 5 \\ \text { None at all } & \text { A little } & \text { Some } & \text { Quite a bit } & \text { A great deal }\end{array}$

Now, consider the CSKA Moscow team (in the red jerseys). Please answer the same questions as before. Think about the performance of this team as a whole when you answer the following questions:

\section{How much hustle did CSKA Moscow show?}

$\begin{array}{lllll}1 & 2 & 3 & 4 & 5 \\ \text { None at all } & \text { A little } & \text { Some } & \text { Quite a bit } & \text { A great deal }\end{array}$

2. How much natural ability did this team have?

$\begin{array}{lllll}1 & 2 & 3 & 4 & 5 \\ \text { None at all } & \text { A little } & \text { Some } & \text { Quite a bit } & \text { A great deal }\end{array}$

\begin{tabular}{|c|c|c|c|c|}
\hline & & 3. How much effort did this team put forth? & 4 & \\
\hline None at all & A little & Some & Quite a bit & A great deal \\
\hline
\end{tabular}


4. How much heart did this team show?

1

None at all

2

A little

3

Some

4

5

5. How much intelligence did this team show?

1

None at all
3

Some
Quite a bit

4

Quite a bit
A great deal

5

A great deal 